\title{
APPLICATION OF NEURAL NETWORKS AND EVOLUTIONARY ALGORITHMS TO SOLVE ENERGY OPTIMIZATION AND UNIT COMMITMENT FOR A SMART CITY
}

\author{
B. Garlik*
}

\begin{abstract}
The optimization problem of two or more special-purpose functions of the energy system is subjected to an analysis. Based on experience of our research and general knowledge of partial solutions of energy system optimization at the level of control of production and power energy supply by energy companies in the Czech Republic, a special-purpose (cost) function has been defined. By analysing the special-purpose function, penalty and limitations have been defined. Using the fuzzy logic, a set of suitable solutions for the special-purpose function is accepted. An optimum of the special-purpose function is looked for using the simulated annealing method. The history of electricity consumption is sorted by day and by hour, representing the multidimensional data. When using the cluster analysis, type daytime diagrams of consumption are defined. Type daytime diagrams form prototypes of identified clusters. The so-called self-organizing neural network with Kohonen map attached is used to perform the cluster analysis. The result of our research is presented by an experiment.
\end{abstract}

Key words: simulated annealing, unit commitment, micro grid, smart area, fuzzy number, optimization

Received: March 5, 2018

DOI: $10.14311 / \mathrm{NNW} .2018 .28 .022$

Revised and accepted: August 8, 2018

\section{Introduction}

Decree of the ERO No. 81/2010 Coll., approved in the Czech Republic, specifies the conditions for the connection of power generating plants and customers' consumption points to the electricity grid and the method of determining the share of the costs connected with connection and provision of the power demand. Further, it specifies the conditions for connection of a local distribution system (LDS) in connection with changes in its balance inside and the conditions for determination and reimbursement of the incurred costs (input/output provision). A new role of the distribution system operators in the management of sources in connection to

\footnotetext{
*Bohumír Garlík; Department of Microenvironmental and Building Services Engineering, Czech Technical University in Prague, Thákurova 7, 16000 Prague 6, Czech Republic, E-mail: bohumir.garlik@fsv.cvut.cz
} 
the operation of the Czech Republic's electricity grid concerns mainly dispatching management, reduction of electricity generation in plants - in the case of sources above $1 \mathrm{MW}$ in connection to construction of technical means of control, operation preparation and transmission of information. A transmission system operator at distribution-system level provides active and reactive power management and emergency management services. Analogously, the RES production management consists in dispatching management in connection to distribution system safety and solution of emergency situations and their prevention. The role of distribution system operators in balance managing is important as well. The distribution system operators are obliged to buy the RES electricity from producers in their area if they so request, and to pay a green supplement charge as set by the Energy Regulatory Office (ERO) to those who sell the RES electricity on the market. The development of Smart Grids and stable energy systems is expected. These grids may adjust automatically the electrical energy consumption as per demand in real time, thereby avoiding daily energy peaks, reducing the risk of overload and overproduction.

Several studies deal with energy saving, but the use of energy resources in an effective way is a problem as well. This is related to the energy balance (EB) expressed by the sum of the electrical energy needs within a building or building area or a Smart City. The EB is expressed by the share of individual renewable sources in energy generation (hydropower, photovoltaics, cogeneration, biomass, distribution system energy- Smart Energy). In an energy system, equilibrium of energy balance applies at each moment, which is expressed by: $S_{v}(t)=S_{s}(t)+S_{z}(t)+S_{a}(t)$, meaning that the generated electricity at time $t$ is $S_{v}(t)$, equal to the sum of the consumed energy at time $t$, which is $S_{s}(t)$, losses caused by the distribution at time $t$, i.e. $S_{z}(t)$, and accumulated electricity at time $t$, which is $S_{a}(t)$. If there is no electrical energy balance in the transmission system, the electrical energy quality is reduced.

The fluctuations in the supply and consumption of a constant amount of electrical energy are considerable on both sides. This is a crucial issue we are solving and presenting in this article. There is an attempt to set up own energy systems, leading to the establishment of so-called local distributed RES microgrids with a combination of a certain electrical energy supply from the distribution system (DS). This leads to implementation of nearly zero-energy buildings, or more precisely, smart areas or smart cities of the same quality. In this way, a local RES microgrid behaves as an energy production plant in a decentralized renewable energy system (DRES).

A nearly zero-energy building is a very low-energy building, where the energy consumption is covered largely by RES. Under Act No. 406/2000 Coll. on energy management (applicable amendments: No. 103/2015 Coll., effective from July 1, 2015, and No. 131/2015 Coll., effective from January 1, 2016). The current state of research in the field of consumption optimizing and power energy source organization - unit commitment for a smart city lies in development of a methodology for building design in the Smart Cities system.

Above all, the characteristic, concept, structure, and approach of smart buildings must be respected as an integral part of the Smart Cities, and then proceed to the following guidance: 
Garlík B.: Application of neural networks and evolutionary algorithms to solve...

a) Basic concepts of Smart Cities buildings

All the buildings integrated into a smart city or its area should be designed as "nearly zero-energy buildings". This category of buildings is defined by the following energy parameters, see Tab. I.

\begin{tabular}{|c|c|c|c|c|c|}
\hline & $\begin{array}{c}\text { Average } \\
\text { heat } \\
\text { transfer } \\
\text { coefficient } \\
\mathrm{U}_{\text {em }} \\
{\left[\mathrm{W} /\left(\mathrm{m}^{2} \cdot \mathrm{K}\right)\right]}\end{array}$ & $\begin{array}{c}\text { Specific } \\
\text { heat } \\
\text { demand } \\
\text { for heating } \\
\mathrm{E}_{H} \\
{\left[\mathrm{kWh} /\left(\mathrm{m}^{2} \cdot \mathrm{a}^{*}\right)\right]}\end{array}$ & $\begin{array}{c}\text { Specific } \\
\text { heat } \\
\text { demand } \\
\text { for cooling } \\
\mathrm{E}_{C} \\
{\left[\mathrm{kWh} /\left(\mathrm{m}^{2} \cdot \mathrm{a}^{*}\right)\right]}\end{array}$ & $\begin{array}{c}\text { Specific } \\
\text { demand } \\
\text { for primary } \\
\text { energy EnP } \\
\text { EnP } \\
{\left[\mathrm{kWh} /\left(\mathrm{m}^{2} \cdot \mathrm{a}^{*}\right)\right]}\end{array}$ & $\begin{array}{c}\text { Total } \\
\text { airtightness } \\
\text { of the } \\
\text { building } \\
\text { envelope } \mathrm{n}_{50} \\
{[1 / \mathrm{h}]}\end{array}$ \\
\hline Family house & $\leq 0.20$ & $\leq 5.0$ & 0 & $\leq 60$ & $\leq 0.6$ \\
\hline $\begin{array}{l}\text { Block of flats } \\
\text { Non-occupied } \\
\text { building }\end{array}$ & $\leq 0.30$ & $\leq 5.0$ & 0 & $\leq 60$ & $\leq 0.6$ \\
\hline $\begin{array}{l}\text { with prevailing } \\
\text { temperature of } \\
18^{\circ} \mathrm{C} \text { to } 22^{\circ} \mathrm{C}\end{array}$ & $\leq 0.35$ & $\leq 5.0$ & $\leq 5.0$ & $\leq 120$ & $\leq 0.6$ \\
\hline Other buildings & \multicolumn{3}{|c|}{ Requirements set individually } & $\leq 120$ & $\leq 0.6$ \\
\hline
\end{tabular}

Tab. I The main energy parameters of "nearly zero-energy buildings" according to their usage (adapted from [39]).

Where the average heat transfer coefficient $U$ em $\left[\mathrm{W} /\left(\mathrm{m}^{2} \cdot \mathrm{K}\right)\right]$ represents the weighted average of partial heat transfer coefficients $U_{i}\left[\mathrm{~W} /\left(\mathrm{m}^{2} \cdot \mathrm{K}\right)\right]$ of individual structures $i$, calculated over the areal representation in the building envelope; specific heating energy demand $E_{H}$ represents the total annual heating energy demand per unit floor area; the specific cooling energy demand $E_{C}$ represents the total annual cooling energy demand per unit floor area; the specific primary energy demand $E_{n P}$ represents the total annual demand for non-renewable primary energy per unit floor area; the total airtightness of the building envelope $n_{50}$ represents the maximum permissible multiplicity of air change in the building interior at a pressure difference of $50 \mathrm{~Pa}$ between the interior and the exterior. In order the solved building to be able to meet the above-mentioned energy parameters, an effective approach must be used at all stages of its design:

b) Mass solution

c) Heat and technical solution

d) Indoor environment

e) Energy solution

It is recommended to be created for the whole territory being solved at once with the examination of energy sharing between buildings. Primarily, it should be focused on renewable energy sources, share of which in consumption 
coverage and its increasing represent one of the main objectives of European states for the future. Several variants should be created from the available options, from which the most appropriate one should be selected by a multicriteria analysis. The energy demand of the area being solved can be covered by energies from the following sources:

- Solar energy (photovoltaic panels)

- Environment energy (heat pumps)

- Wind energy

- Biomass

- Geothermal energy

- Hydropower

- Cogeneration

For our experiment, a variant of the most suitable composition of RES in the application of biomass, photovoltaics, wind energy and cogeneration combined with a certain electrical energy supply from DS was selected.

f) City urbanization:

The concept of Smart Cities is closely related to a phenomenon of recent years - city urbanization with massive resettlement of population on the planet to large urban areas, thereby increasing the concentration of inhabitants and associated activities in urban areas.

For our experiment, the Smart Area was selected as a part of Smart Cities Prague, see Fig. 1, where a comprehensive urban development of smart character is being solved, as a complex of smart buildings meeting the "nearly zero-energy building" conditions.

Based on the assessment of the current state of the energy consumption optimization research, the characteristic features of the "nearly zero-energy buildings" are defined, namely: RES usage, application of quality parameters of construction building envelope elements, efficient building technical systems, and indoor environment quality; see Fig. 2.

a) Photovoltaic panels on building roofs: Free areas of flat roofs of buildings will be used for application of the photovoltaic panels. Parameters of the panels installed: Orientation

- SOUTH; inclination from the horizontal plane $30^{\circ}$; the peak panel output is $320 \mathrm{Wp}$ per panel; the panel efficiency is $13 \%$.

b) Photovoltaic panels on building facades: Free areas of double facades in the second or higher aboveground floors of buildings with favourable world orientation will be used for application of the integrated photovoltaic panels

c) Percentage of facade glazing Facades of different types of buildings will have different percentages of glazing according to the proposed functional type of the building; see Tab. II. 
Garlík B.: Application of neural networks and evolutionary algorithms to solve...

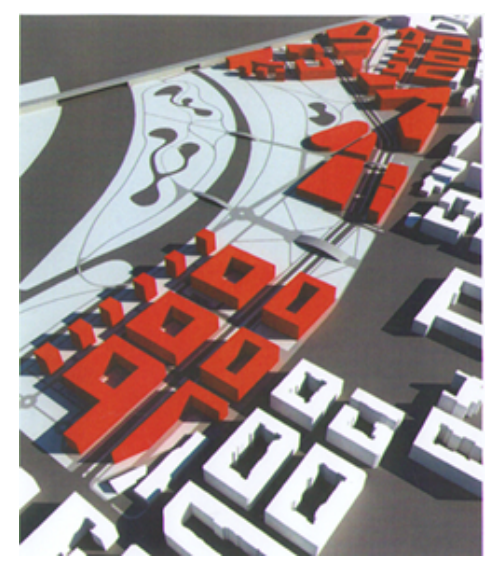

LEGEND:

Proposed buildings

Existing buildings

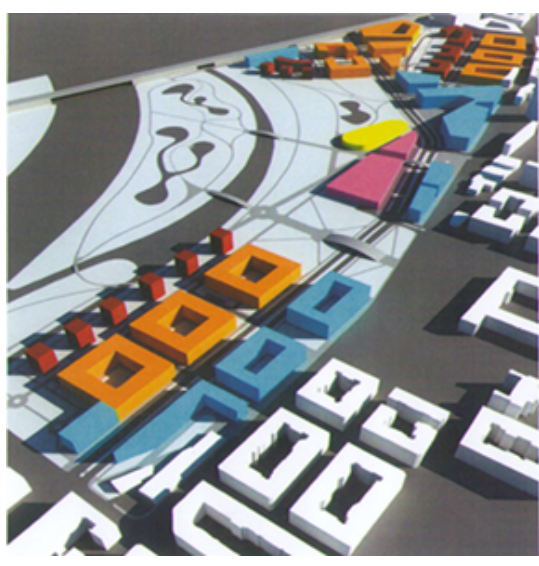

LEGEND:

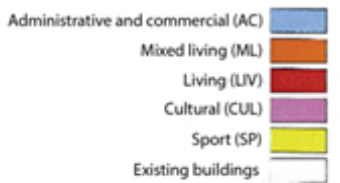

Fig. 1 Smart urban area at Rohanské waterfront, Prague (Taken from: Author of the original urban study is arch. Veronika Soukupová, Czech Technical University in Prague Faculty of Architecture).

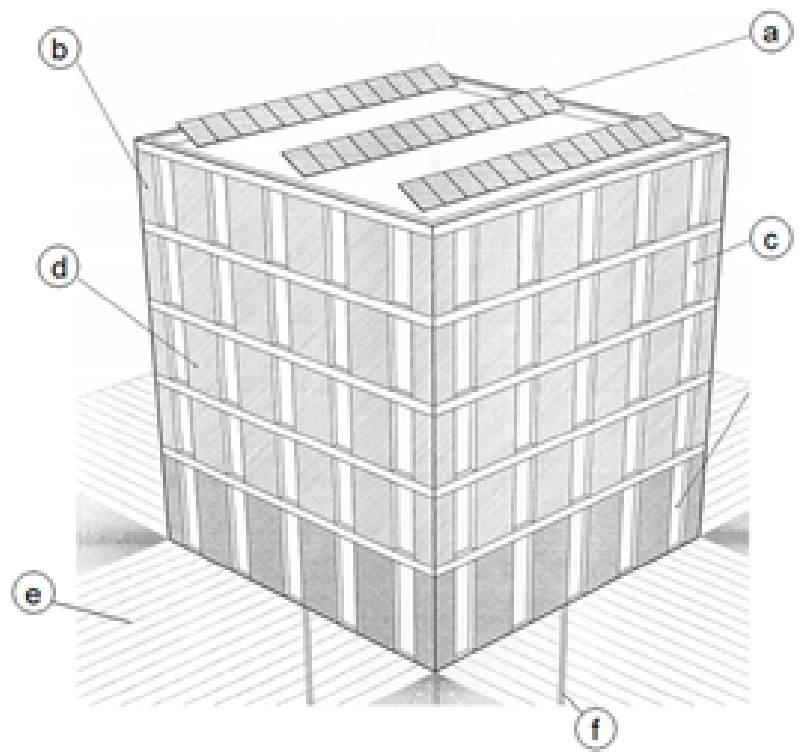

Fig. 2 Building solution schema. A model example. 
Neural Network World 4/2018, 379-413

\begin{tabular}{llcccc}
\hline $\begin{array}{l}\text { Functional } \\
\text { type }\end{array}$ & $\begin{array}{l}\text { Number } \\
\text { of floors }\end{array}$ & $\begin{array}{c}\text { North } \\
{[\%]}\end{array}$ & $\begin{array}{c}\text { East } \\
{[\%]}\end{array}$ & $\begin{array}{c}\text { South } \\
{[\%]}\end{array}$ & $\begin{array}{c}\text { West } \\
{[\%]}\end{array}$ \\
\hline Administrative & 1floors & 20 & 75 & 75 & 75 \\
business & $>$ 1floors & 20 & 50 & 50 & 50 \\
Mixed, living & 1floors & 20 & 75 & 75 & 75 \\
& $>1$ floors & 20 & 35 & 35 & 35 \\
Only living & 1floors & 20 & 35 & 35 & 35 \\
& $>1$ 1floors & 30 & 35 & 35 & 35 \\
Cultural & 1floors & 20 & 50 & 50 & 50 \\
Sport & 1floors & 15 & 15 & 15 & 15 \\
\hline
\end{tabular}

Tab. II Percentage of building facade glazing in a smart area (adapted from [39]).

d) Building envelope properties: Thermal properties of the building envelopes are designed according to principles and requirements of the passive construction standard. Demand for the construction of nearly zero-energy buildings (NZEB) is based on the Directive 2010/31/EU of the European Parliament and of the Council on the energy performance of buildings. The main indicator of thermal and technical properties of the building envelope is to achieve the required heat transfer coefficient $U_{\text {pas }, 20}\left[\mathrm{~W} /\left(\mathrm{m}^{2} \mathrm{~K}\right)\right]$ - it has very wellinsulated structure, quality windows and doors. Annual energy consumption for heating of a passive building depends on the building location and ranges from $1 \mathrm{kWh} / \mathrm{m}^{2}$ in Central Europe to $30 \mathrm{kWh} / \mathrm{m}^{2}$ in Northern Europe. In our Smart Area experiment (Rohanské waterfront, Prague), all the required heat transfer coefficient values of the building envelope are achieved; see [7].

e) Building parterre solution: The parterre of the proposed buildings will be solved with emphasis on maximizing the proportion of green areas used for rain-water retention in the territory

f) Geothermal heat pumps: Ground-plan of the buildings will be utilized effectively to locate deep boreholes of geothermal heat pumps.

Deep boreholes parameters:

Borehole depth

$150 \mathrm{~m}$

Specific output of the borehole taping $\quad 100 \mathrm{~W} / \mathrm{m}$

Axis bore spacing

$10 \mathrm{~m}$

Heat pump parameters:

Percentage of heat loss coverage of a given building $\quad-75 \%$

Proposed heat pump factor COP

While adhering to the mentioned characteristic features of nearly zero-energy buildings, we will define subsequently the specific issues that need to be solved within the research. This is a solution to optimize power consumption and unit 
commitment for a smart city. The considerable fluctuations in the supply and consumption of a constant amount of electrical energy on both sides represent an issue. The ability to influence the amount of electrical energy consumed is ensured by a mass remote control system that enables the appliances to be switched on and off at high and low tariff periods. However, development of modern technologies offers more flexible options for individual consumers. Then, they may obtain a reward from grid operator to reduce or increase their consumption. They are not subject to mass control, but they can influence the activity of household appliances on their own. To do this, however, it is necessary to have real-time data on energy consumption.

The intent and goal of the project - research is to solve the development of function for planning the supply and consumption coordination of different types of energy, in our case the electrical energy of the smart building compound within the Smart area or Smart Cities in a given time period. The aim is to minimize the operating costs for the electrical energy supply and their implementation into a building control system. We consider the electrical energy to be energy medium for the buildings within Smart area as a part of Smart Cities. The electric microgrid is powered by both the distribution system and its local sources, i.e. cogeneration units (CHP), various accumulator types (ACCU), and RES, such as photovoltaic panels (PVP) and biomass power plants (BPP). Mainly, the electric microgrid load of the building compound consists of heating, ventilation and air conditioning (HVAC) systems, transport systems, such as lifts and escalators, information systems, such as computer networks or various sensors, actuators, and eventually conventional electric appliances, lighting, etc.

\section{Multicriterial optimization}

If we want to use more criteria to find the optimum, then their selection is decisive in order to interpret the results correctly. The number of criteria should not be too high, otherwise the results would be difficult to formulate. In this case, it is appropriate to determine the sequence of the objective functions considered.

Multi-Objective Optimization Problem (MOOP) is based on the optimization of two or more objective functions for which we are looking a minimum or maximum and is generally defined by the relation

$$
\min \{f(\mathbf{x}) \mid g(\mathbf{x}) \leq 0, \mathbf{x} \in \mathbf{X}\},
$$

where:

$f(\mathbf{x})=\left(f_{1}(\mathbf{x}), f_{2}(\mathbf{x}), \ldots, f_{k}(\mathbf{x})\right)^{\mathrm{T}}$ is a vector of criterion functions $g(\mathbf{x})=\left(g_{1}(\mathbf{x}), g_{2}(\mathbf{x}), \ldots, g_{p}(\mathbf{x})\right)^{\mathrm{T}}$ is a vector of restrictive condition $\mathbf{x}$ is a solution vector.

The above entry does not specify the role of multicriterial programming unambiguously, since the meaning of the minoperator for the given vectors is not precisely defined. The task is to find such a vector $\mathbf{x}$ that meets the restrictive conditions and in which the criterion functions $f_{1}(\mathbf{x}), f_{2}(\mathbf{x}), \ldots, f_{p}(\mathbf{x})$ reaches values as high as possible.

Let $\mathbf{x}_{1}$ and $\mathbf{x}_{2}$ are acceptable solutions. Let us say that within the solutions of $\mathbf{x}_{1}$, the $\mathbf{x}_{2}$ solution dominates, if $f_{k}\left(\mathbf{x}_{1}\right) \geq f_{k}\left(\mathbf{x}_{2}\right)$ applies to all the $k=1, \ldots, p$, 
wherein such $r$ exists that $f_{r}\left(\mathbf{x}_{1}\right)>f_{r}\left(\mathbf{x}_{2}\right)$. This means that $\mathbf{x}_{1}$ must be better at least according to one criterion, while it is not worse according to any another one. Let us say that solution $\mathbf{x}$ is non-dominant (optimal by Pareto) if there is no acceptable solution to make it dominant. The solution fulfils the condition of Pareto optimality if no criterion can be improved without worsening another criterion.

There is no universal computational method for multicriterial optimization tasks, but there are a number of different methods and procedures that make it possible to find the best compromise solution for a given task. Their basis is the one-off or repeated use of single-criterion optimization methods and, in terms of their breakdown, an interactive method is the most appropriate for our case, where supplementary information about the preferences of a decision-maker is provided only during solving the task.

Issue of the multicriterial decision-making: There is a set of possible variants (decisions, solutions) and we have to choose such variant that is the best one with respect to a given set of criteria (aspects, characteristics). In our case, it is a role of multicriterial programming. The admissible variants are defined implicitly. Generally considered criteria are usually conflicting. In our experiment, qualitative criteria are taken into account that allow only to determine whether a variant is better or worse than another one, or whether the two variants being compared are equivalent under such criterion.

In addition, however, there are also specific methods that use the finiteness of a set of variants and are able to work with qualitative criteria. These include methods based on the theory of fuzzy sets (vague or misty sets) that we will use for our experiment. In these methods, based on the partial preferences of a decision maker, a vague relation is constructed, from which a non-vague preference relation is obtained using thresholds or preference and indifference, or dispreference; the variants can be arrange in some way using such non-vague relation.

\section{Optimization of energy system special-purpose system}

The special-purpose function $f(\mathbf{x})$ is a function whose optimization will lead to find optimal values of its arguments. The special-purpose function is sometimes called a "price function", even in our case it has its place. If we look at optimization with a condition, then we can describe it mathematically as follows

$$
\begin{gathered}
\text { minimization } f(\mathbf{x}) \\
\text { under restricitve condition } g_{i}(\mathbf{x}) \geq 0, \quad i \in I, i=k^{\prime}+1, \ldots, k \\
h_{j}(\mathbf{x})=0, \quad j \in J, j=1,2, \ldots, k^{\prime}
\end{gathered}
$$

$f: \mathbb{D} \rightarrow \mathbb{R}, \mathbb{D} \subseteq \mathbb{R}^{d}$ is defined above the definition field $\mathbb{D}$, which is a continuous set of searched space and $\mathbb{R}$ is a real value range.

Furthermore, $f, g_{i}$ and $h_{j}$ are the functions are and $I$ and $J$ are the final sets of indices. The function $f$ is a special-purpose function and $g_{i} i \in I$, are constraints using the inequality equation, and $h_{j}, j \in J$, are constraints using the equality 
equation. From a general point of view, the optimization problem can be expressed as follows

$$
\min f(\mathbf{x}) \text { for } \mathbf{x} \in \mathbb{R}^{n} \text {. }
$$

The special-purpose function can be expressed as a sum of quadrates of the deviations between the current parameter values and the values required

$$
f(\mathbf{x})=\sum_{i=1}^{m}\left[y_{i}(\mathbf{x})-d_{i}\right]^{2} .
$$

The value of the minimized special-purpose function, or the value of the optimized system parameters, depends on the status vector

$$
\mathbf{x}=\left[x_{1}, x_{2}, \ldots, x_{n}\right]^{\mathrm{T}},
$$

where:

$x_{1}, x_{2}, \ldots, x_{\mathrm{n}}$ are the state variables of the optimized system expressed by the special-purpose function,

$y_{1}, y_{2}, \ldots, y_{m}$ are parameters of the optimized system,

$d_{1}, d_{2}, \ldots, d_{m}$ are the required values of these parameters.

By inequality constraint, the condition $g_{i}(\mathbf{x}) \geq 0$ indicates that the state variable must be higher than or equal to zero. If we multiply both sides by the coefficient of -1 , we get the condition that the state variable is less than or equal to zero, as well as the function of the state variables.

The search methodology for our optimization task is as follows [1]

$$
\min \{f(\mathbf{x}): \mathbf{x} \in \mathbf{X}\},
$$

where $f: \mathbf{X} \rightarrow \mathbb{R}$ and $\mathbf{X} \subset \mathbb{R}^{n}$.

If our problem is formulated from the point of maximization, then it is easy to make the adjustment to minimize. In that case, the situation would be the following [1]

$$
\begin{gathered}
\max \{f(\mathbf{x}): \mathbf{x} \in \mathbf{X}\}=-\min \{-f(\mathbf{x}): \mathbf{x} \in \mathbf{X}\}, \\
\arg \max \{f(\mathbf{x}): \mathbf{x} \in \mathbf{X}\}=\arg \min \{-f(\mathbf{x}): \mathbf{x} \in \mathbf{X}\} .
\end{gathered}
$$

For the local minimum, following applies

$$
\text { on } \mathbf{X} \subset \mathbb{R}^{n} \text {, if } \delta>0 \text { so that, }
$$

for each $y \in \mathbf{X},\|y-x\|<\delta$ applies $f(\mathbf{x}) \leq f(\mathbf{y})$.

For the global minimum, following applies

$$
\text { on } \mathbf{X} \subset \mathbb{R}^{n} \text {, if for each } y \in \mathbf{X} \text { applies } f(\mathbf{x}) \leq f(\mathbf{y}) \text {. }
$$

The special-purpose function design is a very complex problem, requiring considerable experience in the subject area, and the possibilities of defining the optimization must be also taken into account. We need to build on the basis of what is to be achieved and what can be come out. We drew on the experience of our research and the overview of optimization solutions for energy systems of energy companies 


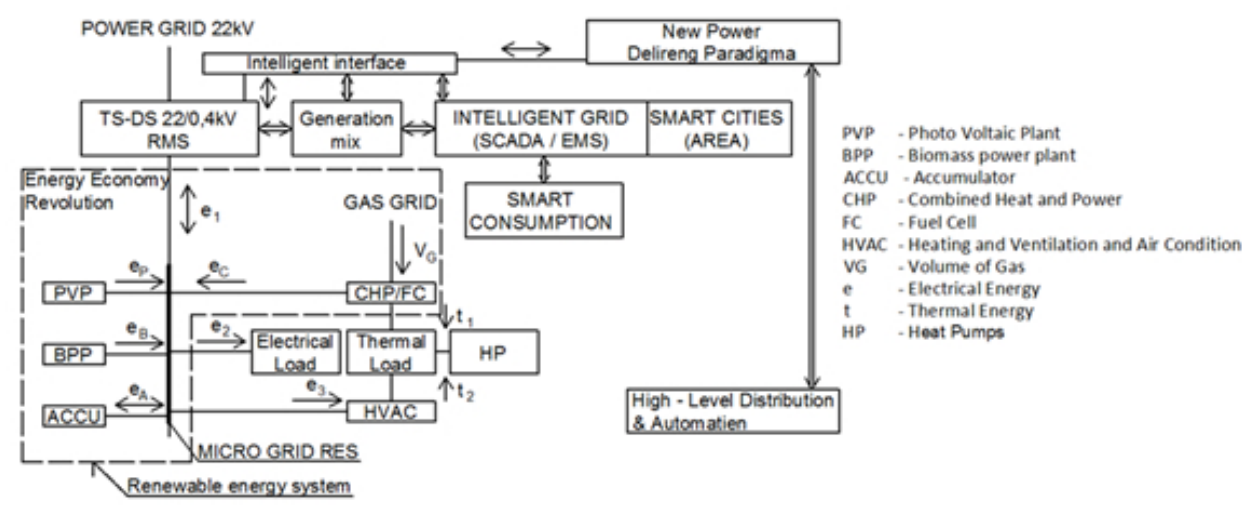

Fig. 3 Model of Intelligent Cities Energy System.

within the Czech Republic. Based on this, we described the physical model of the energy grid - RES microgrid, see Fig. 3, which corresponds to our experiment.

When developing a mathematical model, we draw on the analysis of the system, its overall behaviour and the set solution objectives. Within objective reality, we define a system, i.e. elements, links, inputs and outputs, processes and functions. We make some simplification of the problem to separate irrelevant issues from the essential ones. We identify the most important parts of the system being examined; this system will be modelled, therefore, the identified parts must describe the model to be created. The mathematical model describes the system [9] using a set of variables, constants, and a set of equations or inequalities determining the relations between them. The variables represent some system properties. In each mathematical model, we can distinguish three basic groups of objects the model is composed of: variables and constants, mathematical structures, and solutions. In our case, this is a mathematical structure that is called restrictive conditions. This is a system of equations or inequalities.

Mathematical model of a problem is a special-purpose function. The solution of our mathematical model is to define a suitable solution of a special-purpose function that either meets or does not meet the restrictive conditions. Another objective is to find an optimal solution that suits the best the desired aim, i.e. the optimal solution of the special-purpose function.

When developing this special-purpose function in terms of economically efficient RES electrical energy supply, the computational process, where the total demanded generation is divided among the individual electrical energy sources in operation, is carried out through minimization by the selected cost criterion [11]. Therefore, we the special-purpose function is called a cost function. This cost function is subject to a certain load restriction as well as operational load. For a particular load condition, the output of each power plant is calculated by minimizing the total cost of its production and system operation [3]. Traditionally, this problem is formulated 
as a cost-function optimization, which is defined as a quadratic function [3]:

$$
f\left(P_{g}\right)=\sum_{i-1}^{N_{g}}\left(\alpha_{i}+\beta_{i} P_{g i}+\gamma_{i} P_{g i}^{2}\right) .
$$

If the variable $P_{g}$ (function argument) is expressed as $P_{g i}$ i.e. the output of $i$-th source at time $t$ and $x_{i}(t)$ is energy state of the $i$-th source at time $t$; the basic relation of the cost function is obtained

$$
f\left(P_{g}(t), x(t)\right)=\sum_{i=1}^{N_{g}} \sum_{t=1}^{\mathrm{T}}\left(\alpha_{i}+\beta_{i} P_{g i}(t)+\gamma_{i} P_{g i}^{2}(t)\right) \cdot x_{i}(t) .
$$

Based on the above-defined variables, constants, mathematical approximations and mathematical structures (1) and (2), two variants of the cost functions of our energy system are developed - a physical model of the Intelligent Cities Energy System, see Fig. 3. This is supported by [8] as well.

$$
\begin{array}{r}
f\left(P_{g}(t), x(t)\right)=\sum_{t=1}^{\mathrm{T}} \sum_{i=1}^{N_{g}}\left(\alpha_{i}+\beta_{i} P_{g i}(t)+\gamma_{i} P_{g i}^{2}(t)+\delta_{i}\left(1-e^{-\alpha t}\right)\right) \cdot \mathbf{x}_{i}(t) \\
f\left(P_{g}(t), x(t)\right)=\sum_{t=1}^{\mathrm{T}} \sum_{i=1}^{N_{g}}\left(\alpha_{i} P_{g i}+\beta_{i} P_{g i}^{2}\right) \cdot x_{i}(t)+\gamma_{i} P_{g i} x_{i}(t) \cdot\left(1-x_{i}(t-1)\right) .
\end{array}
$$

When based on the cost function (4) defined over the entire integrated period (24 hours/day), the RES operating costs and the start-up costs of the RES organization have to be separated. The starting point is the fact that the cost function is determined by mathematical approximation of economic indicators obtained empirically. We will define individual variables, constants, mathematical structures, etc.:

- The cost function is referred as $f$;

- Number of RES in the grid is referred as $N_{g}$;

- Time of the scheduled RES organization mode (24 hours) is referred as $t \in$ $\{1,2, \ldots, T\}$;

- The resource index is referred as $i \in\left\{1,2, \ldots, N_{g}\right\}$;

- The number of time moments in a given period when the RESs are deployed is referred as $T$;

- The output of the i-th source at time $\mathrm{t}$ is referred as $P_{g i}(t)$;

- The operational costs of the cost function $f$ are expressed as an algebraic shape $\left(\alpha_{i} P_{g i}+\beta_{i} P_{g i}^{2}\right) x_{i}(t)$;

- The start-up costs to run one of the RES have an algebraic shape $\gamma_{i} x_{i}(t)$. $\left(1-x_{i}(t-1)\right)$; 
- The start-up costs (to start the RES operation) in relation to (3) are expressed by the relation $\delta_{i}\left(1-e^{-\alpha t}\right) \cdot x_{i}(t)$; as well; $\alpha=-\frac{\Delta \mathrm{T}_{i}}{\tau_{i}}(t)$;

- The cost coefficients in relation (3) and (4) are $\alpha_{i}, \beta_{i} \gamma_{i} \delta_{i}$ and $\Delta T_{i}(t)$, respectively; and $\tau_{i}$ are the relevant cost coefficients, or the downtime and time constant of exponential increase in the start-up costs of the $i$-th source at time $t$;

$$
\alpha_{i}[\mathrm{CZK}], \beta_{i}[\mathrm{CZK} / \mathrm{MW}], \gamma_{i}\left[\mathrm{CZK} / \mathrm{MW}^{2}\right], \delta_{i}[\mathrm{CZK}]
$$

- The operating costs of RES generating an output are expressed in an algebraic relation $P=\alpha+\beta \cdot P+\gamma \cdot P^{2}+\delta \cdot e$,

- $x_{i}(t)$ is the energy state of the $i$-th source at time $t$,

- $\left(x_{1}, x_{2}, \ldots, x_{n}\right)$, are the vector components (independently variable of the cost function),

where $N_{g}$, or $T$ is a number of sources in the network or a number of time sectional views considered in the period of running of the sources.

The cost (special-purpose) function (4) is broken down in such shape to describe the significance of the individual coefficients. In particular, the operating costs of RES (one source is selected) producing the output $P_{g}=\alpha \cdot P_{g i}+\beta \cdot P_{g i}^{2}[\mathrm{CZK}]$ are expressed. This relation is specified without expressing the start-up costs. This relationship simplifies the Eq. (4) as the generators (RES) are always $\mathrm{ON}_{i}(t)=1$. In this case, the individual variables (cost items) mean:

$\alpha$ Costs dependent on the output generated (e.g. fuel quantity depending on higher output); [CZK/MW], example $\alpha_{i} \cdot P_{i}=[\mathrm{CZK}]$.

$\beta$ Costs dependent on the second power of the output generated (e.g. Joule heat losses $Q$ is generated in a live wire (winding of generator at a wind power plant within the RES), through which the electric current flows for the time $t$. The higher current passing through the wire (generator winding), the higher losses. Then, Joule heat is $Q=R I^{2} t[\mathrm{~J}]$. In addition, there may be losses in iron and due to friction $\left[\mathrm{CZK} / \mathrm{MW}^{2}\right]$

$P_{g}$ generated output $[\mathrm{MW}]$.

The suitable solutions of the cost function are determined by the condition that the state of the source in the given hour is given by the sum of outputs of the sources switched on, consumed outputs and total output lost.

$$
\begin{gathered}
\sum_{i=1}^{N_{g}} P_{g i}-\sum_{i=1}^{N_{D}} P_{D i}+P_{z t}=0 \\
\text { s.t } V_{\min } \leq V \leq V_{\max } \\
P_{g i, \min } \leq P_{g i} \leq P_{g i, \max }
\end{gathered}
$$

where $N_{g}$ is the total output generated by the all RESs; $N_{D}$ is the total output consumed; and $P_{z t}$ is the total output loss within the system; $\mathbf{x}_{i}(t)$ is the energy 
state of the $i$-th source at time $t ; P_{g i}$ is the output of RES electrical energy source; $P_{D i}$ is the output consumed; $P_{g i, \text { min }}$ is the minimum output of the RES electrical energy source; $P_{g i, \max }$ is the maximum output of the RES electrical energy source; $P_{g}$ is the rated output of the RES electrical energy source; V is the RES source voltage; $V_{\min }$ the minimum RES source voltage; and $V_{\max }$ is the maximum RES source voltage.

The restrictive conditions include balances and imbalances that represent energy equations, as well as restriction of generator, bus, voltage, and current flow. This can be solved using analytical programming such as Non-Linear Programming (NLP), Quadratic Programming (QP), Linear Programming (LP), Newton's method, Internal Point Methods IPM, and decision support methods, such as the Analytical Hierarchy Process (AHP), where the solving of decision-making issues has to take into account all the elements influencing the analysis result, the relations between them, and the intensity with which they interact.

The computational methods used to solve such problem require simplification of the cost function to be linearly and monotonically incremental in parts, but it suffers from the problem of nonconvex behaviour of the energy system, leading to local minimization or local optimality. In this case, we use alternative methods such as Evolutionary Programming (EP) [11], genetic algorithm (GA) [12], search taboo [13], neural networks [14], particle swarm optimization $[15,16]$ optimization stochastic algorithm of simulated annealing (SA) [17], and ADP (adaptive dynamic programming); these are passive learning methods to improve the performance of the economic delivery algorithm.

\subsection{Unit commitment}

Unit Commitment Planning covers the scope of decisions on hourly operation of the RES system with a horizon of one day to one week. The following must be taken into account:

a) Operating restrictions and unit cost.

b) Production and reserve restrictions.

c) Restrictions at power plant start-up.

d) Network restrictions.

In order to follow the above-mentioned restrictions, certain unpredictability, or stochastic variables, certain assumptions need to be fulfilled to formulate unit commitment. For example, a device for rotary reserve of electric current generator, a device for initial reserve under reduced boiler conditions (in the case of biomass), or partial formulation with operation start - start of the electric current rotary generator must be defined. The first restriction to be met is that real electrical energy generation must be higher than or equal to the sum of the total electrical energy demand (output) by consumers and the required system output reserve.

$$
\sum_{i=1}^{N_{g}} P_{g i}(t) \geq P_{\text {cel }}+P_{\text {rez }}
$$


$P_{\text {cel }}$ - total required output [MW],

$P_{\text {res }}$ - total output reserve $[\mathrm{MW}]$.

Should the RES units keep a certain reserve, the upper limits must be adjusted accordingly. Therefore:

$$
P_{g i}^{\max }=P_{g i}^{\mathrm{cap}}-P_{g i}^{\mathrm{res}},
$$

$P_{g i}^{\max }$ - is the maximum output power of the $i$-th RES source [MW],

$P_{g i}^{\text {cap }}$ - output capacity of the $i$-th RES source [MW],

$P_{g i}^{\mathrm{res}}$ - output reserve of the $i$-th RES source [MW],

$$
P_{\mathrm{pop}}+P_{\mathrm{zt}} \leq \sum_{i=1}^{N} P_{g i}-\sum_{i=1}^{N} P_{g i}^{\mathrm{res}},
$$

$P_{\text {pop }}-$ output demand [MW],

$P_{\mathrm{zt}}-$ output loss $[\mathrm{MW}]$,

$$
\gamma_{c}=\gamma_{0}\left(1-e^{\alpha t}\right)+\gamma_{L}
$$

where:

$\gamma_{c}$ - costs of the off-line source run (source status at a given hour) [CZK],

$\alpha$ - thermal time constant of the unit (source),

$t$ - time $[\mathrm{s}]$,

$\gamma_{L}-$ labour costs to fill the units [CZK],

$\gamma_{0}$ - costs of running a cold boiler [CZK],

$P_{g i}^{\max }$ - the maximum output power of the $i$-th source [M],

$$
\gamma_{\mathrm{ban}}=\gamma_{B} t+\gamma_{L}
$$

where:

$\gamma_{B}-$ costs of running a reduced source $[\mathrm{CZK}]$,

$t$ - time $[\mathrm{s}]$,

$\gamma_{\mathrm{ban}}$ - wage costs $[\mathrm{CZK}]$.

Applying the Lagrangian relaxation a better relaxation is obtained, and, therefore a better upper estimation for optimal value than using the normal integer relaxation. It belongs to classical techniques used for the unit commitment problem, where the limitations are based on stochastic variables and predictability is taken into account. For these reasons, and then for reasons that will be discussed in Chapter 4 "Simulated Annealing", the stochastic optimization method will be used to solve this problem because its randomness is a good approach to such solution. Therefore, a stochastic algorithm inspired by physical laws, i.e. simulated annealing, will be applied for unit commitment solution. The suitable solutions of the cost function are determined by the condition that the output state of the source in the given hour $\gamma(t)$ is given by the sum of outputs of the sources switched on. It is based on the daily output consumption type diagram at the given time. Then, the optimization algorithm works only with the suitable solutions [8], which can be evaluated directly through the cost function without any penalty. Then, the following can be written

$$
\sum_{i=1}^{N_{g}} P_{i} \mathbf{x}_{i}(t)=\gamma(t) \text { for } t=(1,2, \ldots, 24)[\mathrm{h}] .
$$


By adjusting the Eq. (5), the relation for the restrictive condition of the cost function is get using relation $\min \{f(\mathbf{x}) \mid g(\mathbf{x}) \leq 0, \mathbf{x} \in X\}$ and the relation Eq. (5) is get. The fact (reality) will be such that $g\left(\mathbf{x}_{i}(t)\right) \geq 0$. Then, the relation can be written

$$
g\left(\mathbf{x}_{i}(t)\right)=\sum_{i=1}^{N_{g}} P_{i} x_{i}(t)-\gamma(t) \geq 0,
$$

where $x_{i}(t)=\left(x_{1}(t), x_{2}(t), \ldots, x_{7}(t)\right)$. Dependency $\overrightarrow{\mathbf{x}}(t)=\left(\mathbf{x}_{1}(t), \mathbf{x}_{2}(t), \ldots, \mathbf{x}_{7}(t)\right)$ depends on the state of the source at a given hour.

Where $\sum_{i=1}^{N_{g}} P_{i} x_{i}(t)$ represents the electrical energy generation at time $t$ and $\gamma(t)$ represents a prediction of consumption at a given hour. Parameters $i \in$ $\left\{1,2, \ldots, N_{g}\right\}$ specify the source index and $N_{g}$ is the number of sources of local RES microgrid; in our case, these are 7 (ten). In addition, $t \in\{1,2, \ldots, T\}$ indicates the time of planned source organisation mode and $P_{g i}(t)$ is the power of the $i$-th source at time $t$.

\subsection{Penalty function}

When using the penalty method, the optimization algorithm works with both suitable and unsuitable solutions. The penalty function in relation to standardized requirements acquires the value of zero; for a solution not meeting one criterion, for example, it acquires the value of nonzero, i.e. it is positive. Defining the penalty function, for example by adding it to cost (special-purpose) function, depends on its complexity in terms of the effectiveness of searching for local optima. Always, it depends on the algorithm used. We will consider one of many approaches to penalizing our cost function, see e.g. $[18,19]$.

First of all, let's express: Definition 1: Considering the functions $f, g$ and assuming that some values of the function $g(x)$ belong to $D(f)$. Such value $u=$ $g(x) \in D(f)$ can be assigned the value $y=f(u)=f(g(x))$. This is a definition for a new function $h(x)=f(g(x))$, which is called a function composed of functions $f, g$ and is referred as $h=f \cdot g$. Note: The function $g$ is applied as first, the function $f$ as second. The penalty function will be directed to the position of unsolicited electrical energy supply that can be expressed as

$$
f\left(\mathbf{P}_{g}(t), \mathbf{x}(t)\right)=(f(\mathbf{X})+a) \cdot \prod_{i=1}^{m} c_{i}^{b_{i}}
$$

where $\mathbf{x}(t)=\mathbf{X}=\left\{x_{1}, x_{2}, \ldots, x_{D}\right\}, D=7$ minimizing functional of $f\left(\mathbf{P}_{g}(t), \mathbf{x}(t)\right) \equiv$ $f_{\text {cost }}(\mathbf{X})$, which is a special-purpose function and, further, $c_{i}=1.0+s_{i} \cdot g_{i}(\mathbf{X})$ if $g_{i}(\mathbf{X})>0$, or $c_{i}=1$ otherwise $s_{i} \geq 1, b_{i} \geq 1 ; \min (f(\mathbf{X}))+a>0$.

Where individual parameters have the following meanings: a ensures that the cost (special-purpose) function $f\left(\mathbf{P}_{g}(t), \mathbf{x}(t)\right)$ will acquire non-negative values only. The parameter a is set to high values, not affecting the optimization process. The constant $\mathrm{s}$ is applied to transform the functional into a suitable scale, and b copies the searched hypersurface. The constraint $g(X)$ is expected to be low, then the higher values for $\mathrm{s}$ and $\mathrm{b}$ are used. Very often, the penalty works satisfactorily with the parameters $s=1$ and $b=1$. 
In our case, this is an external penalty function that links penalty to violations of conditions. The penalty applies only outside the suitable solutions. The most common external penalty is the one that uses the quadrate rate of exceeding as a penalty, see [22]. Let's have a limited minimization task [23]

$$
\min f(\mathbf{x}) ; g_{i}(\mathbf{x}) \leq 0, i=1, \ldots, m ; h_{j}(\mathbf{x})=0, j=1, \ldots, l,
$$

Replacing

$$
\min f(\mathbf{X}, \mathbf{g})=f(\mathbf{X})+a \sum_{j=1}^{l} h_{j}^{2}(\mathbf{X})+a \sum_{i=1}^{m}\left(g_{i}\right)^{2}(\mathrm{X})
$$

where $a=a_{1}, a_{2}, \ldots, a \rightarrow \infty$

At $h_{j}(\mathbf{x})=0, j=1, \ldots, l$, the following is obtained:

$$
\min f(\mathbf{x}, \mathbf{g})=f(\mathbf{x})+a \sum_{i=1}^{m}\left(g_{i}\right)^{2}(x) .
$$

Then, when applying and including the Definition 1 , the restrictive conditions (5) and the relation (6) to the target function $f g(\mathbf{X})$ or when applying the Definition 1 and the conditions (5), (8) and (9), the modified expression of [24] is obtained as:

$$
\mathrm{fg}(\mathbf{X})=\mathrm{f}(\mathbf{X})+\mathrm{a} g^{2}(\mathbf{X}) \approx \min ,
$$

where $a g^{2}(\mathbf{X})$ is so-called penalty of non-required electrical energy supply. Because $g^{2}$ is a negative number, there is a power when $\gamma(t)>\sum_{i} P_{g i} \mathbf{x}_{i}(t)$. The functional value of the target function (10) must be artificially reduced or increased, then $\mathrm{w}$ is the weight in order the two addends in the Eq. (10) are the same. Then we look for such $\mathrm{x}$ to minimize both functions $f(\mathbf{X})+a g^{2}(\mathbf{X})$. In this case, we will solve Eq. (10) by minimizing the cost function $f(\mathbf{X})$ and maximizing the penalty expressed by the function $a g^{2}(\mathbf{X})$. This is how I optimize the special-purpose function.

The sum of the two functions fg compiled from the special-purpose function $f$ and the restrictive-condition function $g$ will provide a new function

$$
\mathrm{fg}(\mathbf{X})=\mathrm{f}(\mathbf{X})-\mathrm{a} \mu(g(\mathbf{X})) .
$$

The "minus" sign is in the Eq. (11) because we want to maximize the functional prescription $a \mu(g(\mathbf{X}))$. The restrictive-condition function $g$ expresses a deviation of the stable output balance, so we need to adjust it to zero. The function $g(\mathbf{X})$ ranges from 0 to 1 and $\mu$ is fuzzy number zero.

Both restrictive conditions in relations (10) and (11) are compared in terms of the results, from which the formulation of restrictive conditions is better. If $f g(\mathbf{X})$ is approaching to the minimum (as we desire), then we are talking about stable energy output balance. The goal of our experimental task follows from it, i.e. to minimize operation costs and minimize generation deviation from consumption.

Note: There may be a case where the electrical energy consumption in the smart urban area at a certain time will be higher than the generated electrical energy, 
then the relation (5) will be a negative number, therefore the defining condition is promoted by the second power, see the relation (6). If (5) is very small (or zero) it will be a satisfactory solution.

Let us to outline the experiment solution:

1. Basis is the Eq. (11). Let us focus on penalizing the non-required electrical energy supply to the smart area from the local RES grid. Weight $w$ (coefficient) defines the cost function conditions. It enters the costs and the balance deviation in the numerical ratio; it is set so that the cost and balance ratios match approximately.

2. Then, we proceed to the condition of extending the set of admissible solutions.

(a) We proceed to make a small admissible deviation of consumption from electrical energy generation.

(b) We organize the outputs of individual sources so that the desired output at a given time approaches to the required consumption as much as possible.

(c) We accept a small admissible deviation and mark it $\Delta P$, see Fig. 4 and the relation (12), which is the equation of a line with negative and positive slope.

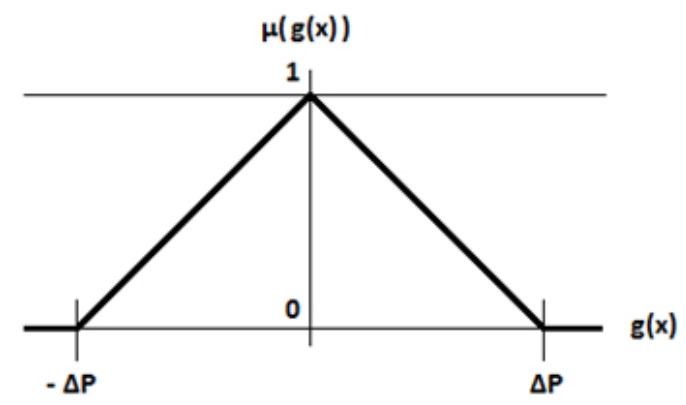

Fig. 4 Affiliation function of triangular fuzzy number of zero $f$ [8].

We assume that the most common type of fuzzy numbers is a triangular fuzzy number their affiliation function is in the form of a triangle, Fig. 4. Let us have $\mathbf{X}=0$, which is a classical set, and $\mu g: \mathbf{X} \rightarrow\langle 0,1\rangle$ is a representation [3]. In this case, the fuzzy set will be called an ordered pair $A=(\mathbf{X}, \mu g)$. In our case, $g$ expresses a deviation of the stable output balance and, therefore, we try to mathematically adjust it to zero. The set $\mathbf{X}$ is labelled as a universe of the fuzzy set $A$ and $\mu g$ is the affiliation function of the fuzzy set $A$ (from where the admissible deviation is defined). Obviously, for each $x \in X$, just the real number $\mu(g)(\mathbf{X}))$ can be called as a degree or level of affiliation of the element $\mathrm{x}$ to the fuzzy set A. [We describe and compare the expressions $\mathbf{x} \equiv g(\mathbf{X})$ and $\mu A(X) \equiv \mu(g(\mathbf{X}))]$. Then, $\mu(g(\mathbf{X}))$ can be expressed as follows 


$$
\begin{aligned}
& \mu(g(\mathbf{X}))=(\Delta P-|g(\mathbf{X})|) / \Delta P \text { in the case when } g(\mathbf{X}) \in\langle-\Delta P, \Delta P\rangle \\
& \mu(g(\mathbf{X}))=0 \text { in the case when } g(\mathbf{X}) \notin\langle-\Delta P, \Delta P\rangle .
\end{aligned}
$$

From the above triangular fuzzy number of zero, it can be assumed $\Delta P=0$ that the restrictive condition $\mu(g(\mathbf{X}))=1$ is fulfilled. In relation $(11), f(\mathbf{X})$ is optimized so that it is minimized, and the subtrahend is maximized (the subtrahend has in the product $\mu=0$ up to 1 is small). Fuzzy number of zero " $m u$ " will be small always against the subtrahend and we can even up it by the weight $\mathrm{w}$ (therefore, we maximize $f(\mathbf{X})$ ). Up to this point, we have solved the optimization task formulation for the need for other optimization task applications to minimize the special-purpose (cost) function.

\section{Simulated annealing}

Optimization means the search for state values of state space (State Space, Search Space), on where the special-purpose (target or cost) function $f(\mathbf{x})$ is defined. It is about finding a global extreme (maximum or minimum) of the special-purpose function. The domain of definition of the function $f(\mathbf{x})$ is given by a set of constraints as we mentioned in the previous section. These limitations can be realized, for example, by means of a set of linear, possibly non-linear equations. The points of the domain of definition are referred as suitable solutions. In practice, we encounter two basic types of optimization - "model" and "technical". The model optimization is understood as situation where the problem presented is defined by a suitable mathematical model (1), (2), (3), and (4). This mathematical model represents a special-purpose function that is mostly analytical, or it is available through a computer procedure. Therefore, the functional value evaluation at the given point does not take too long and we can afford a high number of functional calls (100 000; 1000 000; etc.). Under the model optimization, the problem of the RES energy system can be included, for example. Another situation occurs in the case of technical optimization. In this case, the special-purpose function is not analytical and may not be available even through a computer procedure.

According to the results presented in [20], the simulated annealing is one of the most successful traditional stochastic optimization algorithms. Therefore, it could be faster and more accurate than genetic algorithms. Each call of the specialpurpose function is used directly to scan the state space, without the need of any excess calls of the special-purpose function. During the simulated annealing run, the whole state space is scanned globally, later (at a lower temperature, the probability of receiving a worse solution is lower), the simulated annealing is rather local.

A detailed description of selected optimization techniques can be seen in [4] and [5], for example. Then, we will introduce a typical simulated annealing algorithm, see the Algorithm 1, in a simplified form in JAVA, which shows to be a lot more effective in its complex form. A complex module of simulated annealing software for our task and solution in the experiment is not mentioned here for its scope. 


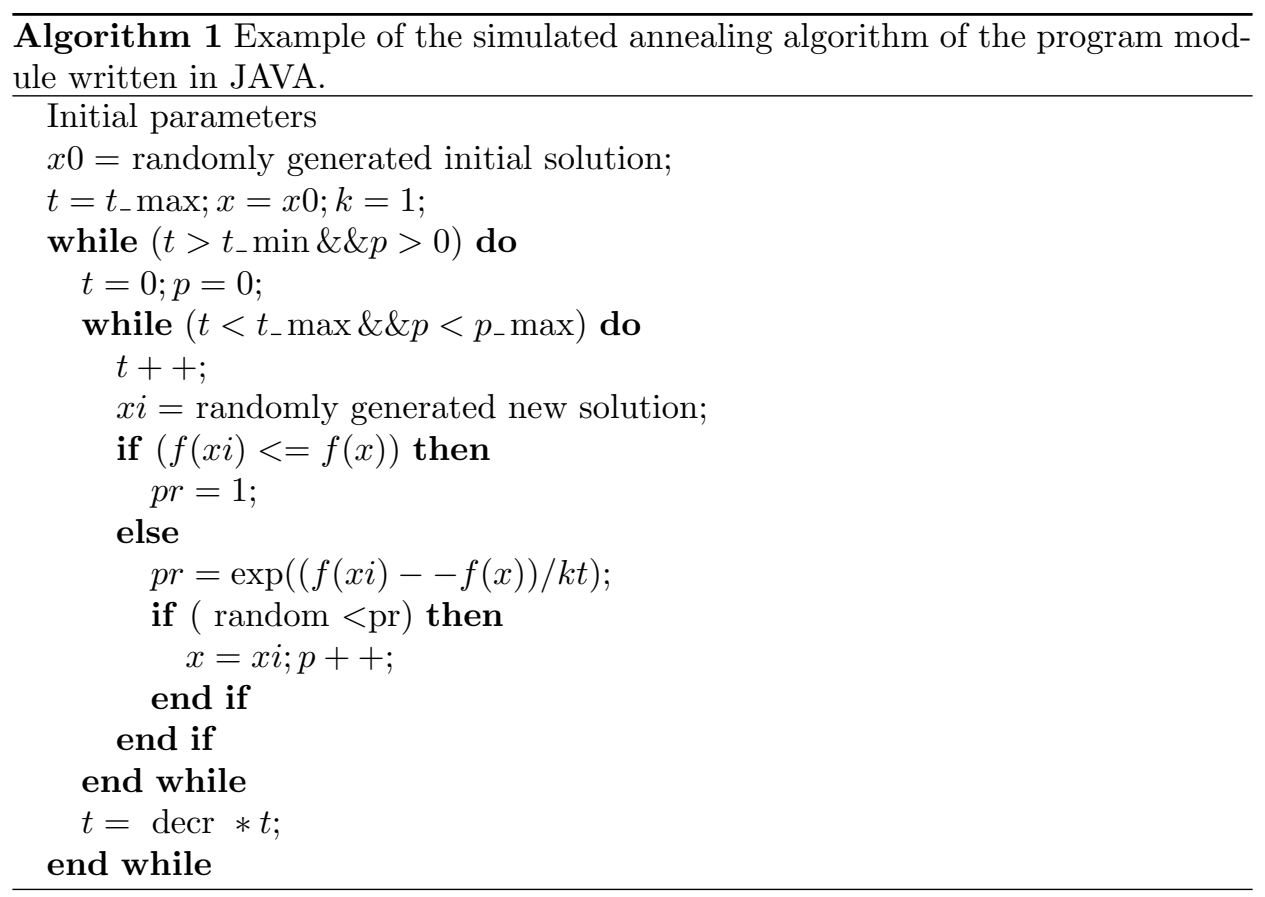

At the beginning, a random solution is generated to evaluate the objective cost function. Another randomly generated solution $x^{\prime}$, for which a replacement existing solution with a probability according to the Metropolis criterion applies, which is referred to as a relation (13) taken from the literature [6]

$$
\text { Probability }\left(x \rightarrow x^{\prime}\right)=\min \left\{1, \mathrm{e}^{-\frac{f\left(\mathbf{x}^{\prime}\right)-f(x)}{k T}}\right\} .
$$

The probability of replacing a current solution with a new solution is that this probability depends on the functional value of the special-purpose (cost) function for each solution. If the original solution has a functional value of $x$ and if it is worse than or the same as the functional value of the newly generated solution $\mathbf{x}^{\prime}$, then the probability of replacement is just equal to one, and the next new solution automatically moves to the next metallurgical SA process

$$
\begin{gathered}
f\left(\mathbf{x}^{\prime}\right) \leq f(\mathbf{x}) \\
\text { Probability }\left(x \rightarrow x^{\prime}\right)=1 .
\end{gathered}
$$

If the functional value of the original solution $\mathbf{x}$ is better than the functional value of the newly generated solution $\mathbf{x}^{\prime}$, the probability of replacement is less than 1 and its value is determined, see the relation (15)

$$
\begin{gathered}
f\left(\mathbf{x}^{\prime}\right)>f(\mathbf{x}), \\
\text { Probability }\left(x \rightarrow x^{\prime}\right)=\left\{\mathrm{e}^{-\frac{f\left(x^{\prime}\right)-f(x)}{k T}}\right\} .
\end{gathered}
$$




\subsection{Conclusion and comparison of optimization methods and evaluation of selection of simulated annealing method}

From the tests given in [21] and [26], the stochastic optimization algorithm of simulated annealing results as the most suitable one. Only if we have a small number of functional calls available, it may be better to use a stochastic mountaineering algorithm. The question of further investigation remains the optimal setting of constants in these algorithms and the testing of algorithms for more functions. Furthermore, the stochastic algorithm implementation has to be adjusted so that they can be used to optimize under more general state space constraints, creating a versatile tool to optimize the general black-box functions.

The first notable feature of the stochastic methods is that they try to eliminate the disadvantage of the gradient method, which is early convergence to a local extreme. This happens by randomly deciding during the search of state space, and we can move, with a certain probability, to a worse solution than the best solution found by us. The early convergence can be prevented by extending the deterministic algorithm by running it several times and each time from different starting point. The great advantage of stochastic algorithms is that they allow us to work with "black box" functions without further modifications, that is, with functions that we cannot analytically describe, but we are only able to evaluate the functional value at any point. The stochastic algorithms include, for example, simulated annealing, adaptive scanning method, stochastic method of branches and boundaries, but also news from the evolutionary algorithms. The evolutionary algorithms include, for example, SOMA (Self Organizing Migration Algorithm), Differential Evolution, Ant Colony Optimization, Immunology System Method, and, primarily, the genetic algorithms.

To analyse and compare each method, the computational results from testing the methods presented in [20] were used. We have found out that the calculation of the stochastic algorithm complexity requires a sufficient number of information on the special-purpose function that are not available sometimes. In our experiment, the shape of special-purpose (cost) function is known and we know a satisfactory number of information about it. For this reason, the quality of the algorithm ("complexity") will be evaluated using the number of "redundant" calls of the special-purpose function, i.e. those that are not used directly to search the state space.

\section{Experiment}

Let us assume that there is a fictitious Smart City formed by a complex of smart buildings of residential, administrative and public character of a wide range of civic amenities, see Fig. 1.

The energy concept of the area under consideration is clearly focused on local renewable energy sources, which use portion of the heat and electricity needs as much as possible. The essence of the energy concept of the given area on Fig. 1 is the interconnection of photovoltaic systems from the whole territory (PS1, PS2, PS3, PS4, and PS5) into one large system including the biomass and cogeneration 
with an energy centre in substation for TS-DS 22/0.4 kV; RMS (see Fig. 3) in the centre of smart area on the underground floor of the building KU02. Such system reacts more flexibly to the current electrical energy demand in sub-operations and, at the same time, provides the use of all the energy currently generated as per the unit commitment optimization plan directly in the territory. This eliminates the problem that would arise with systems separated for each building, selling of excesses to a grid from one house and, at the same time, buying energy from the grid of the neighbouring house.

This is a RES microgrid at a distance of up to $50 \mathrm{~km}$ from the Smart City. In order to ensure a continuous and reliable electrical energy supply, two high-voltage lines of different distributors are brought to the city from the two independent directions. The local microgrid of distributed RES system consists of biomass, cogeneration, and photovoltaic system; see Fig. 3. In the experiment, the complex of smart buildings in urban development is supplied with electrical energy from seven sources, see Tab. III, showing the costs, characteristics, and technical constraints of the individual sources.

\begin{tabular}{cccccc}
\hline UNIT & $\begin{array}{c}\text { State } \\
{[\text { off/on }]}\end{array}$ & $\begin{array}{c}\mathrm{Pn} \\
{[\mathrm{MW}]}\end{array}$ & $\begin{array}{c}\mathrm{A} \\
{[\mathrm{CZK} / \mathrm{MW}]}\end{array}$ & $\begin{array}{c}\mathrm{B} \\
{\left[\mathrm{CZK} / \mathrm{MW}^{2}\right]}\end{array}$ & $\begin{array}{c}\mathrm{C} \\
{[\mathrm{CZK}]}\end{array}$ \\
\hline PS1 & 1 & 140.0 & 190 & 0.50 & 170 \\
PS2 & 0 & 260.0 & 190 & 0.50 & 230 \\
PS3 & 0 & 100.0 & 190 & 0.50 & 123 \\
PS4 & 1 & 50.0 & 190 & 0.50 & 110 \\
PS5 & 1 & 4.0 & 190 & 0.50 & 95 \\
Biomass & 1 & 1.0 & 300 & 0.40 & 173 \\
Cogeneration & 0 & 4.3 & 80 & 0.10 & 85 \\
\hline
\end{tabular}

Tab. III Parameters of Sources RES. Pn is rated output of a RES plant with concurrency inclusion of 0.7. PS - photovoltaic source.

Estimation of electrical energy consumption in the smart urban area at Rohanské waterfront, Prague, is based on the values of the total useful floor area of all buildings in the smart area to estimate the given type of electrical energy consumption and the specific consumption values and the electrical energy consumption values by months per year for each type of buildings and the total electrical energy consumption per year; Tab. IV including financial costs. Tab. V shows the electrical energy generation values per year according to the type of building, including the total electrical energy generation per year from the RES microgrid energy system of the smart area.

Note: $W_{p}\left[\mathrm{kWh} / \mathrm{m}^{2}\right]$ is specific electrical energy consumption per floor area in $\mathrm{m}^{2}, W_{p, \text { rok }}\left[\mathrm{kWh} / \mathrm{m}^{2}\right], W_{\mathrm{sp}}[\mathrm{kWh}]$ is electrical energy consumption per year, $P_{\mathrm{PV}}[\mathrm{kWp}]$ is photovoltaic power plant output.

Note: $P_{\mathrm{PV}}\left[\mathrm{kW}_{p}\right]$ is the photovoltaic power plant output, $701 \cdot P_{\mathrm{PV}}[\mathrm{kWh}]$ is the relation for calculation of electrical energy generated per year by photovoltaic panels located on a given type of building, and CZK is a financial appreciation of the electric energy generated on a given building. $\mathrm{kWe}$ is the unit of electrical power. 


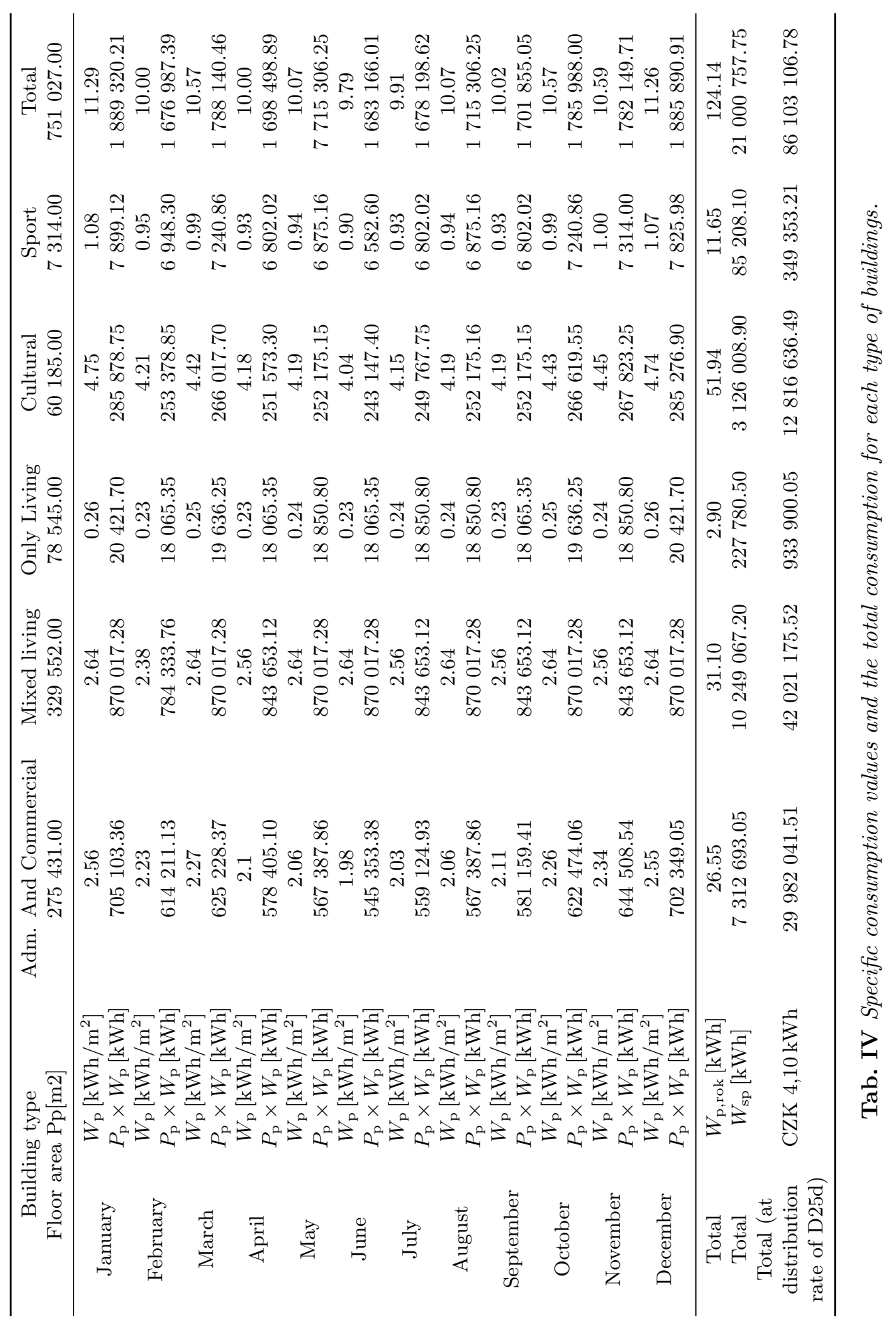


Garlík B.: Application of neural networks and evolutionary algorithms to solve...

\begin{tabular}{lcccc}
\hline Building type & RES & $P_{\mathrm{PV}}[\mathrm{kWp}]$ & $701 \times P_{\mathrm{PV}}[\mathrm{kWh}]$ & {$[\mathrm{CZK}]$} \\
\hline Administrative & PS1 & 2655 & 1861155 & 7630735.50 \\
and Commercial & & & & \\
Mixed living & PS2 & 5251 & 3680951 & 15091899.00 \\
Only living & PS3 & 2036 & 1427236 & 5851667.60 \\
Cultural & PS4 & 1015 & 711515 & 2917211.50 \\
Sport & PS5 & 78 & 54678 & 224179.80 \\
Distribution area & Biomass & $3 \times 1500 \mathrm{kWel}$ & 22680 & 47443.20 \\
Distribution area & Cogeneration & $8600 \mathrm{kWel}$ & 43344 & 7740000.00 \\
Total & $\mathrm{X}$ & 11035 & 7801559 & 39503136.60 \\
\hline
\end{tabular}

Tab. V Electrical energy generation per year according to the building type and total electrical energy generation per year.

\subsection{Self-Organizing Map}

Our experiment aims to define a solution for source organisation system design for a typical working day in the middle of week - Wednesday. After processing the analytical part of the experiment - the optimization project, i.e. minimizing the total cost of generating electrical energy supplied by the RES unit commitment system, where the amount of electrical energy generated is based on prediction (estimation) of consumption during the period under consideration (smart buildings or smart premises in a smart area system) sampled by hours. This is to create a plan of unit commitment and their generated outputs covering predicted consumption at each hour of the period under consideration. Using mathematical analysis with the optimization stochastic method - simulated annealing, we have reached an evaluation and design of the input parameters for the purpose of program module design - a software with application of the JAVA programming language.

The input parameters to the optimization program are:

1. Prediction of load by hours (obtained from the history of experimental scientific observation) - what the electrical energy consumption will be at a given time.

Note: To evaluate this data, a neural network will be used to transmit and process information (data). Furthermore, the neural network will be used to implement and optimize the parameters and structure of a fuzzy model. In addition, the mathematical and information-oriented method of clustering cluster analysis of data - will be used through the data analysis. Several types of daytime diagrams as objects will be created that will be grouped then into "clusters" so that two objects of the same cluster are similar than two objects of different clusters. Individual clusters will result in so-called prototype. These are the prototypes, cost coefficients and restrictive conditions that will be the inputs for the neural network, and, further, these include:

2. Number of electrical energy generators (sources).

3. Number of hours for which the plan is developed. 
4. Cost coefficients for each generator.

5. Predicted consumption per hour of the given period.

6. Weight $w$.

We will apply the cluster analysis method. The annual history of electrical energy consumption will be modelled artificially to compare the identified type daytime diagram with a standard. The basic standard used the characteristic hourly consumption patterns of the working day - Wednesday in July. The individual hourly consumptions were modified randomly using a random number generator with a normal probability distribution. This modelling was performed two hundred and sixty times (the number of Wednesday working days) using the JAVA program. In Figs. 5 and 6, two examples of randomly dialed daily diagrams are selected in the center. In fact, it is an hourly consumption forecast, ie its standards derived from historical data.

We apply the self-organizing neural network (SOM); we call it the Kohonen network. For example, we can imagine a representation of a self-organizing neural network consisting of inputs, individual weights, and so-called competitive neuroncontaining layer. The SOM networks are implemented always with uncontrolled training. The self-organizing principle is the reaction of outputs, i.e. the activation of artificial neurons on input changes. This uncontrolled neural network model collects data into clusters. The Kohonen networks work in analogy to cluster or factor analysis. The point is to reduce the input file by mapping it to a smaller number of clusters.

The Kohonen algorithm is defined as follows:

1. We initialize the weights of neurons by small random values and set the initial value $\alpha(t)$ to the maximum.

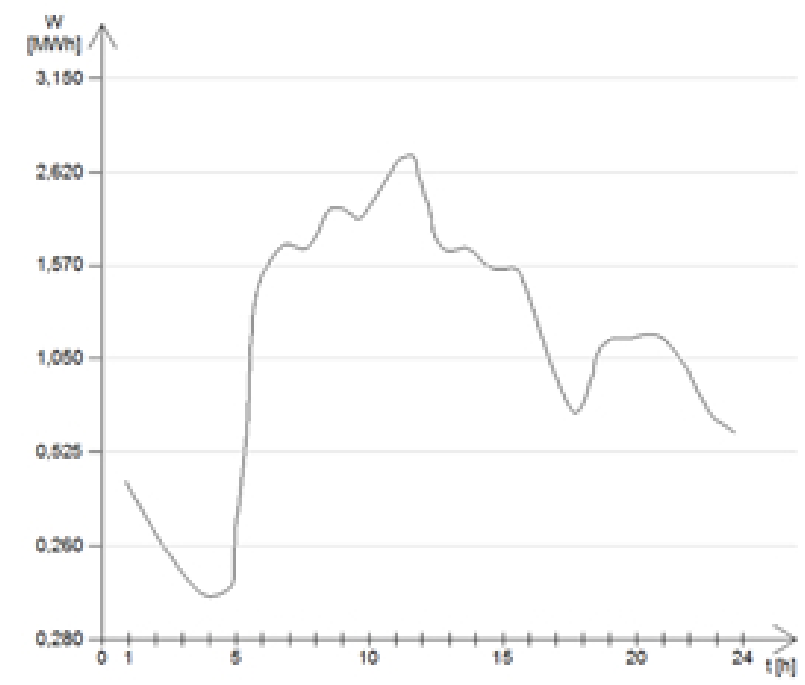

Fig. 5 Type of daily electricity consumption diagram (Wednesday). 
Garlík B.: Application of neural networks and evolutionary algorithms to solve...

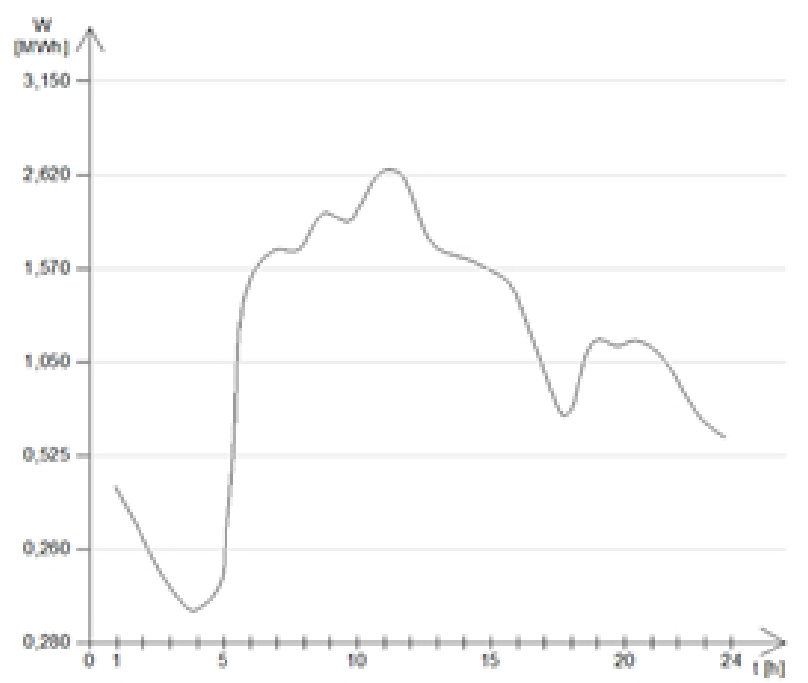

Fig. 6 Standard power consumption chart (Wednesday).

2. We select the vector $\overrightarrow{\mathbf{x}}$ from the learning set and attach it to the network input, i.e. the node $i$ at time $t$. Vector $\overrightarrow{\mathbf{x}}$ is in the form $x_{0}(t), x_{1}(t), \ldots, x_{n-1}(t)$.

3. We calculate the neuron outputs (distances), i.e. determining the competence winner. $y_{i}=\sum_{j=1}^{N}\left(\mathbf{x}_{j}-w_{i j}\right)^{2}$.

4. We determine the winning neuron, which is the neuron with the lowest response, through $y_{i}$ as $j^{*}$.

5. We will adjust the weights for each neuron by $\Delta w_{i j}=\alpha(t)\left(\mathbf{x}_{j}-w_{i j}\right) h(i, b)$. Where $\alpha(t)$ determines the rate of learning (i.e. the variable decreases to zero over time); $h(i, b)$ is the function, which is the maximum if $i$ is the winning neuron index $(i=b)$; ; if it is another neuron, then the function $h$ decreases with the distance from the winner. Where $i=1,2, \ldots, n$ and $j=1,2, \ldots, n$, are the indices passing through the neurons of adjacent layers and $w_{i j}$ is the weight between the $i$-th and the $j$-th neuron. Extreme is 1 for $i=b, 0$ otherwise.

6. If the learning set is not exhausted, we proceed from the point 2 .

7. The coefficient of $\alpha(t)$ is decreased and if it is higher than zero, we continue with the point 2 from the beginning of the learning set.

The learning process is that we submit the pattern to the input and determine the winner. Winner weights are moved a little closer to the vector being learned. In addition to the winner, the adjacent neurons are modified. Then, the procedure is repeated, until $\alpha(t)=0$. is stabilized. 
Recalling can be imagined that a pattern is submitted on inputs and the responses are calculated. The winner, the lowest-response neuron, is a representative of the cluster where the pattern belongs.

Function $h(i, b)$ means how the weights of neurons close to the winner one will change, i.e. how the prototypes represented by neurons will move towards the pattern being learned. The winning neuron will be attracted the most, the neuron that is the most distant from it will be attracted the least. If the function $h(i, b)$ is negative, then the nearest neurons are repelled, in order to barriers between clusters. The learning process begins with an area of $h(i, b)$ that gradually becomes steeper over time.

In the context of the mentioned Kohonen algorithm, the SOMs are applied as one of the artificial intelligence methods for modelling the annual history of hourly electrical energy consumption. Our experiment is a complicated data structure, so choosing the SOM application is a transparent solution. So, a square grid of 52 rows and 24 columns is built.

This grid represents the shape of multidimensional data that form the probability distribution of training patterns. It is a set of neurons, which, during the adaptive dynamics, submit a vector of the learning set to the Competence Model SOM within one day; this vector is attached on the network input determined by 24 attributes at time t. The outputs of the neurons are calculated, the winner is identified, and the weights are adjusted according to point 5 of the Kohonen algorithm (KA) for each adjacent neuron. The next procedure according to KA is obvious from points 6 and 7 .

This principle of adaptation is applied in the so-called Kohonen Map. By this, one can image the finding of spatial representation of complex data structures so that classes of similar vectors are defined by close neurons in a given topology. Following the network adaptation course during the active dynamics, after resubmitting the training patterns, the Kohonen Map will be drawn (Fig. 7), from which the very well-separated most massive cluster corresponding to Wednesday can be found.

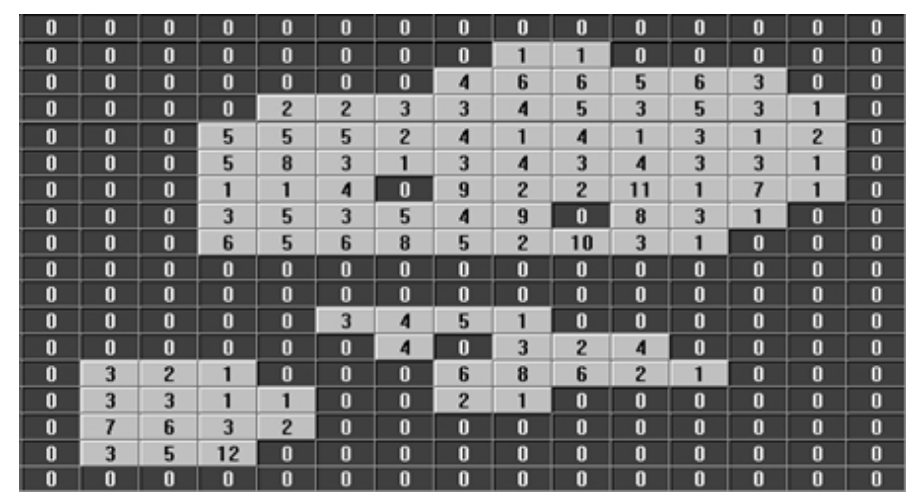

Fig. 7 Kohonen maps of our example.

In addition, by reactive propagation during active dynamics, we can extract the necessary weighing sectors from the configuration of the neural network we learn, 
ie the Type Day Diagrams to be scanned, as shown in Fig. 8, compared to the corresponding standard Fig. 9.

Individual daytime diagrams within the annual history in the Figs. 8 and 9 clearly show that the consumption patterns are quite different. The typical daytime diagrams of consumption are substantially similar to the relevant standards, see Figs. 8 and 9, proving the fact that the cloud analysis method is very effective. Tab. II and Tab. II show the specific power expression of type daytime diagrams () compared to standards.

At the same time, the Tab. IV clearly show that their average and maximum tolerances are about $0.1 \%$ and $0.5 \%$, respectively. From this expression, the cluster analysis method can be said as very effective and high-quality method, which was demonstrated by this experiment.

Here is another example in our experiment. This will provide a smart area with energy from the local micro grid of the RES network. The distributed local micro grid of the RES network is equipped with eight generators combined with the distribution of public electricity and local ACCUs: photovoltaic energy, cogeneration and biomass, Power Grid and ACCU. There are a total of ten sources in total, see Tab. VII.

Another task and objective of the experiment was to propose the unit commitment for one working day of a week, i.e. Wednesday in June 2018. The hourly consumption forecast was processed for the Wednesday, see Fig. 7. The initial temperature setting operation is based on its initial estimate and its subsequent increase to a value, at which almost every failure is accepted during the first ten percent of the repeat. The principle of tuning the number of iterations is based on its initial estimation and subsequent increase to a value, after which there is no decrease in the resulting production cost of the amount of power energy that covers the consumption of the period under consideration. The reference costs of power

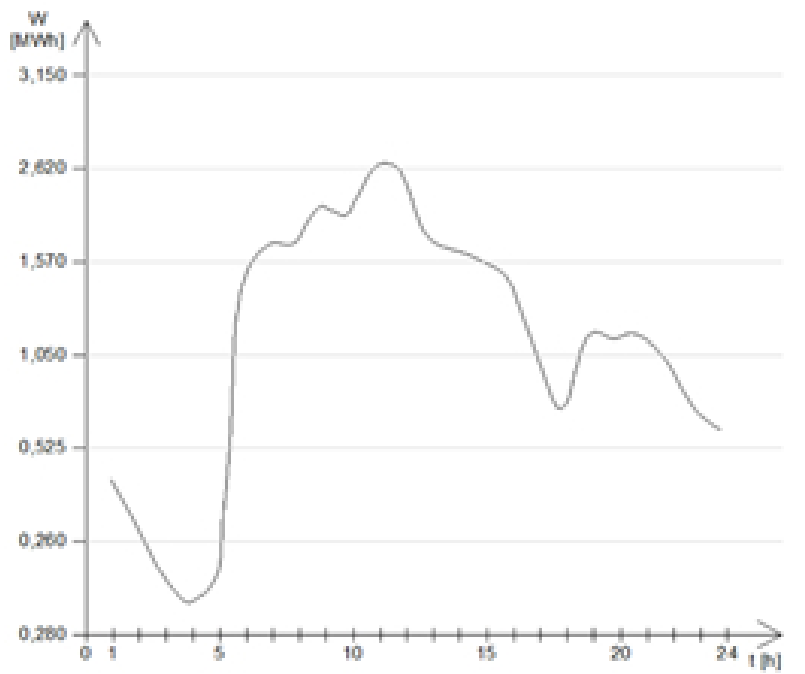

Fig. 8 Typical day diagram of the working day in the center. 


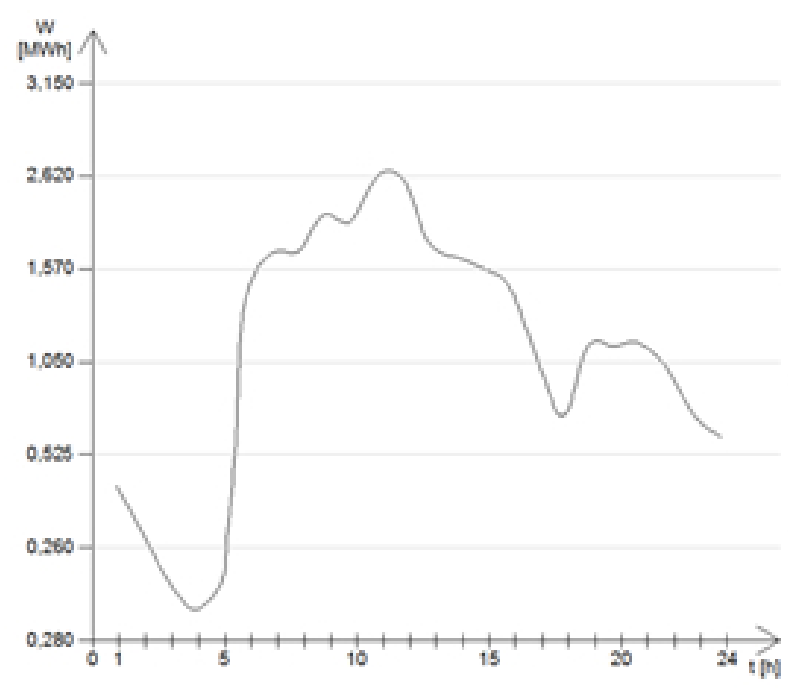

Fig. 9 Standard Day Diagram to Type Day Diagram Fig. 8.

energy generation, which covered the predicted consumption of the period under consideration, were defined by a simplified solution. The simplified solution for the period under consideration consisted in that all sources are working at medium power, see the relation (17).

\begin{tabular}{cccccccc}
\hline \multicolumn{4}{c}{ Wednesday } & \multicolumn{5}{c}{ Wednesday } \\
Time & $\begin{array}{c}\text { TDD } \\
\text { (order of hours) }\end{array}$ & $\begin{array}{c}\text { SDW } \\
{[\mathrm{kW}]}\end{array}$ & $\begin{array}{c}\text { Diference } \\
{[\%]}\end{array}$ & $\begin{array}{c}\text { Time } \\
\text { (order of hours) }\end{array}$ & $\begin{array}{c}\text { TDD } \\
{[\mathrm{kW}]}\end{array}$ & $\begin{array}{c}\text { SD } \\
{[\mathrm{kW}]}\end{array}$ & $\begin{array}{c}\text { Diference } \\
{[\%]}\end{array}$ \\
\hline 1 & 791 & 792 & 0.13 & 13 & 2100 & 2103 & 0.14 \\
2 & 650 & 651 & 0.15 & 14 & 2100 & 2109 & 0.43 \\
3 & 350 & 351 & 0.29 & 15 & 2000 & 2007 & 0.35 \\
4 & 340 & 342 & 0.20 & 16 & 1600 & 1603 & 0.19 \\
5 & 1050 & 1054 & 0.38 & 17 & 1310 & 1313 & 0.23 \\
6 & 2300 & 2307 & 0.30 & 18 & 1560 & 1565 & 0.32 \\
7 & 2300 & 2302 & 0.09 & 19 & 1700 & 1708 & 0.47 \\
8 & 2400 & 2402 & 0.08 & 20 & 1750 & 1754 & 0.23 \\
9 & 2360 & 2363 & 0.13 & 21 & 1570 & 1574 & 0.25 \\
10 & 2620 & 2625 & 0.19 & 22 & 1310 & 1312 & 0.15 \\
11 & 2300 & 2303 & 0.13 & 23 & 1250 & 1251 & 0.08 \\
12 & 2300 & 2304 & 0.17 & 24 & 1050 & 1051 & 0.10 \\
\hline
\end{tabular}

Tab. VI Type daytime diagrams and their standards.

Note: TDD - type day diagram, SD - standard diagram. 
Garlík B.: Application of neural networks and evolutionary algorithms to solve...

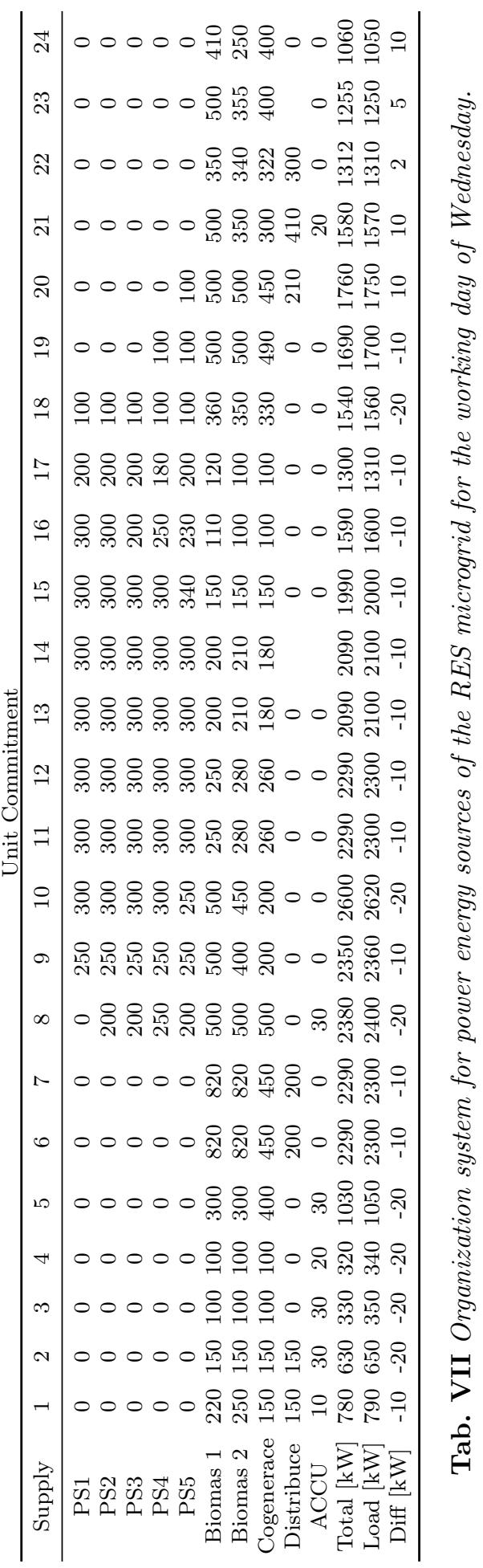




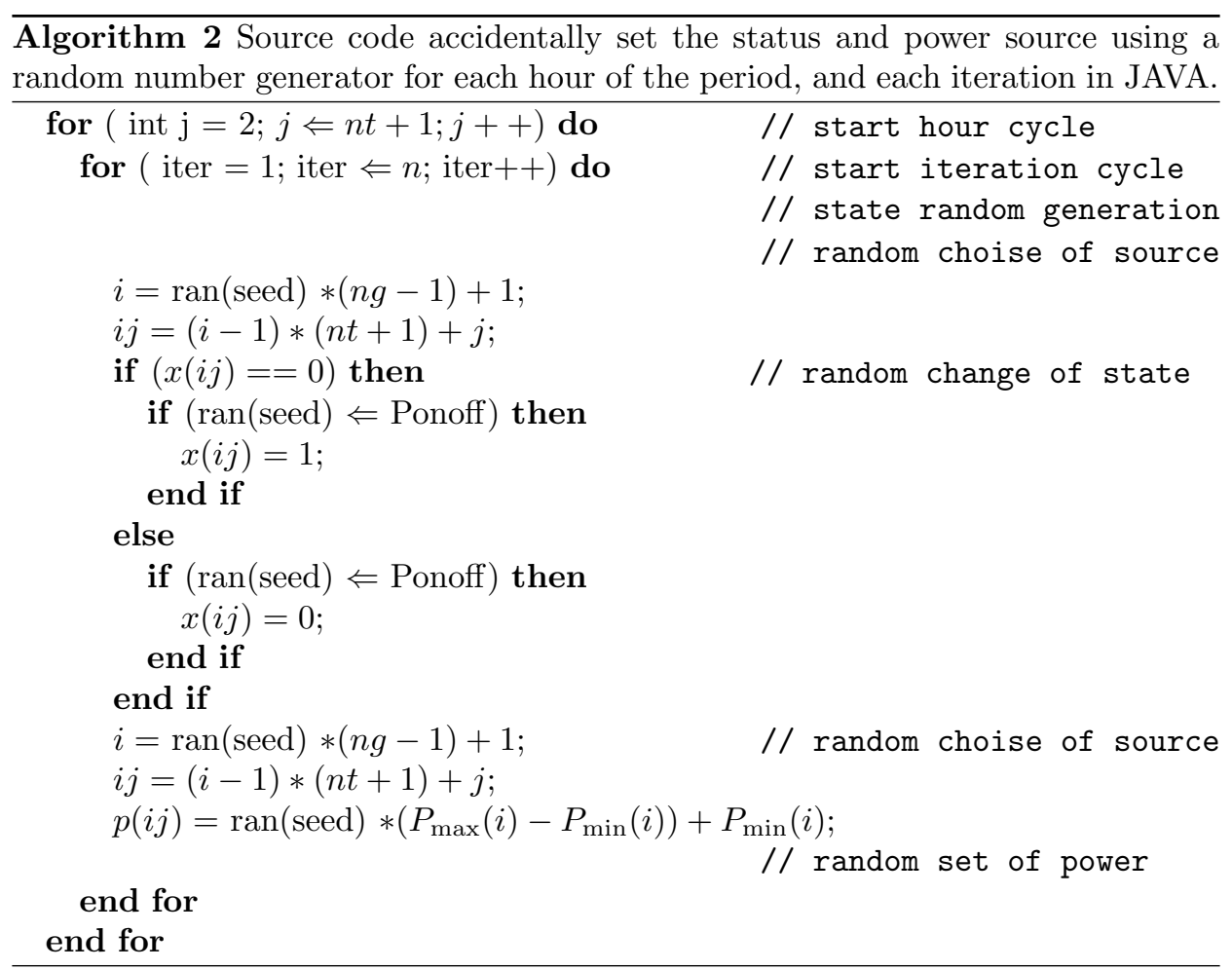

$$
P_{i}(t)=C(t) \frac{P_{i}^{C}}{\sum_{i} P_{i}^{C}} P_{i}^{C}=\frac{1}{2}\left(P_{i}^{\max }-P_{i}^{\min }\right) .
$$

During our optimization Algorithm 2, a random setting of the state and power of a randomly selected source from the RES range is carried out by using a random number generator for each hour of the defined period and for each iteration according to the example of the partly presented source code in JAVA.

Where $n t$ is the number of hours and $n g$ is the number of available resources, $p(i j)$ is the power of the $i$-th source and the $j$-th hour, $x(i j)$ is the state of the $i$-th source and the $j$-th hour. $P_{\min }$ and $P_{\max }$ are the power limits the $i$-th source. $P_{\text {onoff }}$ is parameterizable probability of the source state change, and the RAN function is the said random number generator from the interval $(0,1)$ with even distribution of probability. The result of our experiment from the source organization position for said Wednesday is shown in the Tab. VII. Finally, a remarkable fact that time of calculation made by a laptop was two minutes and thirty seconds.

\section{Conclusion}

According to the ERO in the Czech Republic (Energy Regulatory Office), the circuit breaker payment used for the new tariff calculation should be replaced with the so-called "concurrency" parameter. The creation of a balanced tariff system 
should be managed according to this, for example by introducing a special tariff for consumers with the production plant (RES microgrid), by analysing the reserved input powers, by omitting the primary circuit breaker setting from the design, by using the existing mathematical model of a new tariff structure focusing on the concurrency parameter with a coefficient of 0.2 , by optimizing the existing distribution rates, by analysing the possibility of splitting the tariff system to individual voltage levels, etc. We will build on the concurrency coefficient, which is determined according to the Rusküv formula.

$$
\beta_{n}=\beta_{\infty}+\left(1+\beta_{\infty}\right) \cdot 1 / \sqrt{n}[-]
$$

Where $n$ is the number of flats in the group, $\beta_{n}$ is the concurrency for the considered number of flats in the group, and $\beta_{\infty}$ is the concurrency for an infinite number of flats; for (100 or more), it is $\beta=0.15$ to 0.2 .

Practical assignment is done for a given number of flats, or for a given object using a standard where values of $\beta$ are specified. Then, in the case of large LV grids, other values of concurrency are get in the calculation of the concurrent input power, such as the concurrency between buildings according to the density of consumption at the outlet (according to [27], this value is 0.5 to 0.8 ) or the concurrency between the individual outlets. Based on some experience, we determine the load, i.e. the electrical energy consumption according to the value of the specific consumptions and the total consumption for each type of buildings and its useful area, see Tab. IV.

We define the grid load, i.e. we "estimate" the concurrent prospective load in the expected maximum of individual consumptions, which is the most important step in the grid design. The optimal technical design is based on this load. From this, it follows that determination of concurrency of individual LV sections is one of the most difficult parts of the design and often, it depends mainly on designer's experience.

The total power load (consumption) of the urban smart area of Rohanské waterfront is evaluated at $21000757 \mathrm{kWh} /$ year $=21 \mathrm{MWh} /$ year according to Tab. IV. The total power generation of the electrical energy from the RES microgrid, see Fig. 3 and Tab. V, is $7801559 \mathrm{kWh} /$ year $=7.8 \mathrm{MWh} /$ year. At the concurrency of $\beta=0.6$, the total power consumption of the smart area is $12600454 \mathrm{kWh}$ per year. The installed distributed RES microgrid will cover the power consumption of the urban smart area at $62 \%$ of electrical energy. In the planned concurrency (idea design) according to the ERO by 2020 using the existing mathematical model of the new tariff structure, focusing on the concurrency parameter with the coefficient of 0.2 , it is possible to optimize the existing distribution rates by analysing the possibility of splitting the tariff system to individual voltage levels, reaching significant electrical energy savings. In our experiment, power excess of electrical energy would be $85 \%$, which is $3.6 \mathrm{MWh} /$ year, at the consumption of $4.2 \mathrm{MWh} /$ year. This would ensure that the urban smart area would be self-sufficient in terms of electrical energy consumption, in fact, it would produce $3.6 \mathrm{MWh}$ of electrical energy per year into the distribution $22 \mathrm{kV}$ Power Grid. The smart area would be energetically active in this case and with $85 \%$ of the total volume of electrical energy generated, this portion would be saleable. With the move to smart grids, see Fig. 3, it is assumed that buildings within the urban smart area at Rohanské waterfront will be able to generate energy themselves and act as autonomous traders in the 
energy market. As today, for example, there is an automated exchange system that helps to offset exchange rate differences, a decentralized network of autonomous buildings - power plants - may also emerge in the energy market.

When defining the unit commitment optimization of the RES electrical energy according to the working day (Wednesday) by hours, see Fig. 10, further energy savings are shown graphically, where A is the volume energy saving, B is the volume present, mathematically-defined electrical energy consumption, and $\mathrm{A}+\mathrm{B}$ is the total required current electrical energy consumed on a Wednesday in July. Fig. 10 shows energy savings of about $20 \%$.

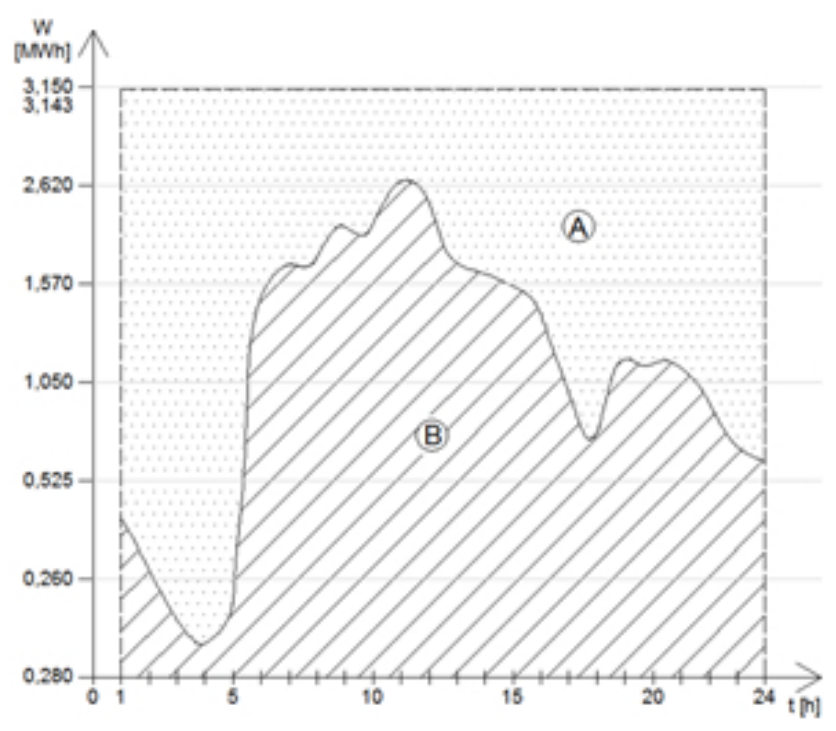

Fig. 10 Other energy savings represented graphically.

By applying cluster analysis and Kohonen map, it can be said that the Tab. VI shows clearly that the average and maximum tolerances between the type daytime diagram and its standard range between approximately $0.1 \%$ and $0.5 \%$. For this reason, cluster analysis method is a very efficient and high-quality method where individual clusters of arbitrary shapes (graphical waveforms over a day by hours) and, eventually, building densities are identified easily. It means that it is a hierarchical clustering that can be imagined as a sequence of buried decompositions that start with trivial decomposition on the one side, where each object of a given set of objects forms a single-element cluster and ends with trivial decomposition on the other side with one cluster containing all objects. It is also evident from the Kohonen map. This method is sensitive to the presence of remote objects that highly differ from all other objects. That is why the degree of similarity is important, and that is our case. Similarity between objects is used as object clustering criterion. First, the characteristics determining the similarity are specified, and these are combined further into similarities. In this way, the object can be compared to another object. Cluster analysis generates clusters of similar objects. Therefore, either one of them or empty set is an intersection of any two clusters. 
Hierarchical models are based on distance connection. In the future, the metrics that are not influenced by this phenomenon are advised to be explored. This is also related to the need to use algorithms able to work with these distances. The $\mathrm{K}$-Medoids method is most appropriate in this case. This is similar to the K-means method, but clusters are not represented by their centre of gravity but one of the cluster points. The advantage of this approach consists in that this representative is determined by the method automatically, it is not necessary to choose it using silhouettes. This method is quite robust in relation to remote objects. Compared to the K-means method, for example, a neural network cluster analysis is completely versatile in relation to the character of the object arrangement in the file to be examined (it is able to identify even uniform distribution of objects in a $n$-dimensional space), but the interpretation of its results is partly dependent on the subjective reading from the Kohonen map.

From our experiment, it can be concluded that the above procedure of solution shows the high efficiency of the optimization SA algorithm in scanning the space of suitable solutions. This efficiency is given by the ratio of the total number of suitable solutions to the simulated suitable solutions at each hour of the defined period; expressed mathematically $10^{75}: 10^{6}$.

\subsection{Sensitivity analysis}

For the sake of integrity of the smart area energy performance solution, for example through our experiment, we will always face the problem, whether a project focusing on the RES use in order to generate the electrical energy for a given urban smart area will be effective. This problem is typical for applying the sensitivity analysis. First, we will name the net present value formulation (NPV). Factually right criterion of the economic assessment is based on the maximization of future cash flows. Given the cost of money over time, the cash flows generated by the implemented project in the future must be converted to an addable value, which is done best by calculating the net present value (NPV) using discounting. The discounting consists in conversion of various monetary variables (net cash generated by a project after taxation in individual years of the project operation) to a suitably chosen moment, which is usually the beginning of the first year of operation. Our project focusing on the RES use for electrical energy generation is a typical example of the sensitivity analysis application. The values are as follows:

1. NPV at change in the investment costs.

2. NPV at selected items of operating expenditure (e.g. on the price of purchased biomass).

3. NPV at discount (expresses impact of expected appreciation of the capital invested on the project effectiveness).

4. NPV at electrical energy generation amount (annual utilization of installed output).

5. Minimum electrical energy price at discount. 


\section{Neural Network World 4/2018, 379-413}

6. Minimum electrical energy price at electrical energy generation amount (annual utilization of installed output).

Of course, there are more possible sensitivity analyses and their selection always depends on the particular case of the project to be evaluated. The sensitivity analysis enables for whom conducts the economic evaluation of the project and decides on its implementation to assess how changes in the assumptions (economic parameters of the evaluated projects) affect the economic efficiency.

When applying the results of the financial evaluation of the RES application of our project according to Tab. IV and V in the context of the unit commitment solution as per Tab. VI and VII, we have come to the conclusion given in Chapter 6 of the Conclusion. The smart area is energetically active, so the project is effectively feasible.

\section{References}

[1] LACHOUT P. Matematické programování (Mathematical programming). Working text for lecture Optimalizace (Optimization) I. 2011. Available at: http://www.karlin.mff.cuni. cz/ lachout/Vyuka/TEXTY/111016-MP_skripta.pdf.

[2] GARLÍK B. The application of artificial intelligence in the proces of optimizing energy consumption in intelligent areas, Neural Network World, 2017, 27(4), pp. 415-445, doi: 10. 14311/NNW. 2017.27.023.

[3] DRUCKMÜLLER M. Technicky orientované lingvistické modely reálných funkcí více proměnných, VUT Brno, KOVS, B-119, 1988.

[4] ZELINKA I., OPLATKOVÁ Z., ŠEDA M., OŠMERA P., VČELǍ̌ F. Evoluční výpočetní techniky - principy a aplikace, BEN - technická literatura, Praha, 2009.

[5] KVASNIČKA J., POSPÍCHAL P., TIŇO P. Evolučné algoritmy, Vydavatelství STU, Bratislava, 2000.

[6] MAYER P. Moderní metody rozvrhování výroby (dissertation), 2003.

[7] TYWONIAK J. Pasivní a nulové budovy na společné cestě. TZB-info, Topinfo s.r.o., 2011.

[8] GARLÍK B., KŘIVAN M. The use evolutionary algorithms to optimize Intelligent Buildings electricity Supply, Neural Network World, 2013, 23(5), ISSN 1210-0552.

[9] KONOPKA A.K., GRABE M.J. Compact Handbook of Computational Biology. Marcel Dekker, 2004.

[10] MOMOH J. Smart Grid: Fundamentals of Design and Analysis, First Edition, IEEE. by John Wiely and Sons, Inc., 2012.

[11] YANG H., YANG P., HUANG C. Evolutionary Programming Based Economic Dispatch with Non-Smoot Fuel Cost Functions, IEEE Transactions on Power Systems. 1996, 11, pp. 112-118, doi: 10.1109/59.485992.

[12] WALTERS D.C., SHEBLE G.B. Genteic Alorithm Solution of Economic Dispatch with The Valve-point Loading, IEEE Transactions on Power Systems. 1993, 8, pp. 1325-1332.

[13] LIN W.M., CHENG F.S, TSAY M.T. An improved Tabu Search For Economic Dispatch with Multiple Minima, IEEE Transactions on Power Systems. 2002, 17, pp. 108-112.

[14] LEE K.Y. SODE-YOME A., PARK J.H. Adaptive Hopfield Neurel Network For Economic Load Dispatch, IEEE Transactions on Power Systems. 1998, 13, pp. 519-526.

[15] EBERHART R.C., SHI Y. Comparing Inertia Weights and Constriction Factors in Particle Swarm Optimization, Proceedings of the 2000 Congres on Evolutionary Computation, 1, pp. 84-88, doi: 10.1109/CEC.2000.870279.

[16] EBERHART R.C., SHI Y. Particle Swarm Optimization: Developmets, Applications, and Resources, Proceedings of the 2001 Congress on Evolutionary Computation, 1, pp. 81-86. 
Garlík B.: Application of neural networks and evolutionary algorithms to solve...

[17] DEKKERS A., AARTS E. Global optimization and simulated annealing. Mathematical Programming, 1991, 50, pp. 367-393.

[18] LAMPINEN J., ZELINKA I., New Ideas in Optimization - Mechanical Engineering Design Optimization by Differential Evolution. London: McGraw-Hill, 1999, 1, 20 p., ISBN 007709506-5.

[19] ZELINKA I. Umělá inteligence v problémech globální optimalizace. Nakladatelství BEN, Praha, 2002.

[20] ÖZDAMAR L., DEMIRHAN M. Experiments with new stochastic global optimization search techniques. Computers and Operations Research, 27, pp. 841-865, 2000.

[21] ŠTEFKA D. Systém pro studium genetických algoritmů v kontextu tradičních stochastických optimalizačních metod. ČVUT Praha, 2004.

[22] HAFTKA R.T., GURDAL Z. Elements of structural optimization. 3rd rev. and expanded ed. Boston: Kluwer Academic Publishers, 1992. ISBN 07-923-1504-9.

[23] KOKRDA L. Optimization of Building constructions with Probability constraints. Brno university of technology. Diploma thesis. Brno 2015. Number of pages 8. Leading diplomats work Dr. Pavel Popela, Ph.D.

[24] GARLÍK B. The Application of artificial Intelligence in the Process of Optimizing energy Consumption in Intelligent areas. Neural Network World, 27(5), 2017, ISSN 1210-0552.

[25] ZELINKA I. SOMA - Self Organizing Migrating Algorithm. In: Babu B.V., Onwubolu G. (eds), New Optimization Techniques in Engineering, Springer-Verlag, 2004, ISBN 3-54020167X.

[26] ŠTEFKA D. Alternativy k evolučním optimalizačním algoritmům. Diploma thesis. ČVUT Praha, 2005. Thesis supervisor Ing. RNDr. Martin Holeňa, CSc.

[27] DSO_ME_0083r03. Všeobecné zásady pro technické návrhy sítí vn a nn. ČEZ Distribuce, a. s., Strategic Development Department, 2008-06-05. 22 number of pages.

[28] PŘIBYL O., SVÍTEK M. Systémově orientovaný přistup k inteligentním městům. In: Proceedings from the first conference of IEEE International Smart Cities. (ISC2-15), in Guandalajara, Mexico, 2015.

[29] SVÍTEK, M., VOTRUBA, P., MOOS, P. Towards Information Circuitis, Neural Network World. 2010, 20(2), pp. 241-247, ISSN 1210-0552.

[30] VLČKOVÁ V., HRUBES P. Dopravní nehoda systémový model a shluková analýza v prostředí GIS, Acta informatica Pragensia. 2015, 4(1).

[31] LOM M., PŘIBYL T., ZELINKA T. System Engineering for Smart Cities, WMSCI, 2016.

[32] POSTRÁNECKÝ M., SVÍTEK M. SynopCity - Virtual HUB for Smart Cities. In: EATIS 2016, Cartagena - Columbia, 2016.

[33] PŘIBYL O., SVÍTEK M. Systém-oriented Approach to Smart Cities, IEEE Systems Man and Cybernetics Society, 2015.

[34] SVÍTEK M. Towards complex systém theory, Neural Network World, 2015, 25(1), pp. 5-33.

[35] ROTHKRANTZ L.J.M. Smart Surveillance Systems Network Topology in Command and Control, Organization Operation and Evolution: Organization Operation and Evolution. IGI Global, 2014.

[36] WALSH M.P., MALLEY M.J. Augmented Hopfield network for unit commitment and economic dispatch, IEEE Trans. Power Syst., 1997, 12, pp. 1765-1774.

[37] SISWORAHARDJO N.S., EL-KAIB A.A. Unit commitment using ant colony search algorithm, Proc. 2002 Large Eng. Syst. Conf. Power Eng., 2002, pp. 2-6.

[38] PADHY N.P. Unit commitment using hybrid models: a comparative study for dynamic programming, expert system, fuzzy system and genetic algorithms, Elect. Power Energy Syst. 2000, 23, pp. 827-836.

[39] HLAVAČEK P. Smart cities vybrané oblasti hl. Města Prahy. Diplomová práce. Vedoucí diplomové práce. Assoc. prof. Dr. Bohumir Garlik. Czech Technical University in Prague, Thákurova 7, 16000 Prague 6, Czech Republic, 2016. 